\title{
Host Specific Plant Growth Promoting Activity of IAA Producing and Phosphate Solubilizing Fluorescent Pseudomonas
}

\author{
Priyanka $^{1^{*}}$, Anil S. Kotasthane ${ }^{1}$, Ashish Pradhan ${ }^{2}$, Umesh Shinde $^{2}$, \\ Toshy Agrawal ${ }^{2}$, Najam Waris Zaidi ${ }^{3}$ and U.S. Singh ${ }^{3}$ \\ ${ }^{1}$ Department of Plant Pathology, Indira Gandhi Krishi Vishwavidyalaya, Krishak Nagar, \\ Raipur (C.G.)-492006, India \\ ${ }^{2}$ Department of Plant Molecular Biology \& Biotechnology, Indira Gandhi Krishi \\ Vishwavidyalaya, Krishak Nagar, Raipur (C.G.)-492006, India \\ ${ }^{3}$ IRRI India Office, New Delhi, India \\ *Corresponding author
}

\section{A B S T R A C T}

Keywords

IAA, PHB,

Phosphorus,

Fluorescent

Pseudomonas

Article Info

Accepted:

28 January 2018

Available Online:

10 February 2018
Fluorescent Pseudomonas possesses many traits that make them well suited as biocontrol and growth promoting agents. Host specific plant growth promoting activity of fluorescent Pseudomonas isolates was observed. Isolates \#P72, P141, P151, P233, P124, P6, P143, P176, P76, P99, P167 were able to induce the formation of increased root and shoot length. Isolates used in the present investigation had the ability (although in different proportions) to solubilize inorganic phosphate, produce Indole acetic acid (IAA) and PHB. Frequency of fluorescent Pseudomonas isolates which induced shoot length of crop plants more than fluorescent Pseudomonas isolates with the ability to induced root length. It was also observed that Fluorescent Pseudomonas isolates reduced root shoot length as compared un-treated control.

\section{Introduction}

Microorganisms, interact with higher plants in soil ecosystem and influences the development of plant root in the soil (Ahmad et al., 2008; Taghavi et al., 2009). Beneficial plant-microbe interactions enhance plant growth and nutrient uptake by different mechanisms, including increased mobilization of insoluble nutrients (Lifshitz et al., 1987; Ahmad et al., 2008), biocontrol of phytopathogenic organisms (Weller, 2007) and/or by production of phytohormones (Dubeikovsky et al., 1993; Spaepen et al., 2007).

Pseudomonas putida are ubiquitous bacteria frequently present in the plant rhizosphere 
(Timmis 2002; Dos Santos et al., 2004) and possess many traits that make them well suited as biocontrol and growth promoting agents (Fravel, 1988; Lemanceau, 1992; Weller et al., 2002; Fravel, 2005) because of their potential to produce secondary metabolites (Leisinger and Margraff, 1979), growth hormones (Brown 1974), antibiotics (Fravel, 1988; Weller et al., 2002) and chelating compounds (siderophores) (Leong, 1986). Phosphate solubilization is one of the direct mechanisms (Rodríguez and Fraga , 1999; Mayak et al., 2004; Shahzad et al., 2010) and production of antibiotics such as 2,4-diacetyl phloroglucinol (DAPG), phenazine, pyoluteorin and pyrrolnitrin against pathogenic fungi and bacteria are among indirect mechanisms of PGPR (McSpadden Gardener et al., 2001; Ramamoorthy et al., 2001). Some of them may also be involved in the biodegradation of natural or man-made toxic chemical compounds(Holloway 1992; Ramos et al., 2009). P. putida show diverse spectrum of metabolic versatility and niche-specific adaptations (Rojo 2010; Wu et al., 2011). Several lines of evidence suggest that PGPB produced IAA which may directly stimulates plant growth, even in the presence of otherwise inhibitory compounds (Wani et al., 2008; Bianco and Defez 2009; Egamberdieva 2009; Bianco and Defez 2010; De-Bashan et al., 2010). IAA synthesized by bacteria may be involved at different levels in plantbacterial interactions. Fluorescent Pseudomonas may alter the suboptimal or optimal endogenous IAA level in plant roots(Pilet and Saugy 1987) to either optimal or supraoptimal, resulting in plant growth promotion or inhibition, respectively. IAAdeficient mutant of Pseudomonas putida GR12-2(Patten and Glick 2002a) had a reduced root length as compared to wild-type $P$. putida GR12-2 which induced the formation of roots that were 35-50\% longer thus suggesting the role of bacterially produced IAA in root development. On the other hand IAA positive mutants (overproducing) of same strains (Pseudomonas putida GR12-2) (Xie et al., 1996), yielded greater number of shorter roots on inoculation of mung bean cuttings as compared to wild type strain. Combined effect of auxin on growth promotion and inhibition of root elongation by ethylene has been reported (Jackson 1991). Apart from primary and secondary metabolite production, certain fluorescent Pseudomonads (especially $P$. putida) are suitable as whole-cell biocatalyzers for the production of several value-added industrial compounds such as biodegradable and biocompatible polyesters called polyhydroxyalkanoates (PHA) or polyhydroxybutyrates (PHB). It accumulates as discrete granules and is used as storage material for carbon and for reducing equivalents by $P$. putida. This property has been widely exploited for their targeted biosynthesis in this organism (Hoffmann and Rehm 2004). Different strains of $P$. putida such as $P$. putida KT2440, $P$. putida GPo1, $P$. putida $\mathrm{S} 12$, etc. have been investigated for its capacity to accumulate PHAs and PHBs from different carbon sources (Durner et al., 2001; Hartmann et al., 2004; Meijnen et al., 2008). The pha gene cluster is responsible for the accumulation of PHAs and PHBs in $P$. putida (Vo et al., 2008; Chung et al., 2009; Wang and Nomura 2010). In the present investigation the potential of IAA producing and phosphate solubilizing fluorescent Pseudomonas on Bottlegourd, Chickpea, Greengram, Lathyrus, Rice, Wheat was studied.

\section{Materials and Methods}

\section{Bacterial isolates}

The experimental material consisted of twenty four isolates of Fluorescent Pseudomonas spp isolated from soil (rhizospheric and nonrhizospheric) samples of different 
geographical locations of Chhattisgarh (Table 1). Isolated bacterial colonies after incubation at $28^{\circ} \mathrm{C}$ for 2 days, were exposed under UV light $(366 \mathrm{~nm})$, emitted fluoresces from the colonies and biochemical tests as per the procedures outlined in Bergey's Manual of Systematic Bacteriology (Sneath et al., 1986) confirmed the identity as fluorescent Pseudomonas. Culture were maintained on King's B broth (Himedia) containing 50\% $(w / v)$ glycerol at $-80^{\circ} \mathrm{C}$ in the Department of Plant Molecular Biology and Biotechnology, Indira Gandhi Krishi Vishwavidyalaya, Raipur, Chhattisgarh, and were revived on King's B slants as and when required.

\section{Screening for polyhydroxybutyrate (PHB) production and its quantitative estimation}

Fluorescent Pseudomonas isolates were screened for PHB accumulation qualitatively by following the viable colony method using Sudan Black B dye (Liu et al., 1998). Sterilized Nutrient agar (Himedia) supplemented with $1 \%$ glucose was spot inoculated with the isolates and incubated at $30^{\circ} \mathrm{C}$ for $24 \mathrm{~h}$. Ethanolic solution $(0.02 \%)$ of Sudan Black B was spread over the colony and the plates were kept undisturbed for 30 min. Later, they were washed with ethanol (96 $\%)$ to remove the excess stain from the colony. The dark blue colored colony was taken as positive for PHB production. The Sudan Black B positive isolates were subjected to quantification of PHB production as per the method of (Law and Slepecky 1961). The bacterial cells containing the polymer were pelleted at 10,000 rpm for 10 min. and the pellet was washed with acetone and ethanol to remove the unwanted materials. The pellet was re-suspended in equal volume of $4 \%$ sodium hypochlorite and incubated at room temperature for $30 \mathrm{~min}$. The whole mixture was again centrifuged and the supernatant was discarded. The cell pellet containing PHB was again washed with acetone and ethanol. Finally, the polymer granules were dissolved in hot chloroform. The chloroform was filtered and to the filtrate, concentrated $10 \mathrm{ml}$ hot $\mathrm{H}_{2} \mathrm{SO}_{4}$ was added. The addition of sulfuric acid converts the polymer into crotonic acid which is brown colored. The solution was cooled and the absorbance was read at $235 \eta \mathrm{m}$ against a sulfuric acid blank. By referring to the standard curve prepared using Poly[(R)-3-hydroxybutyric acid] (Sigma Aldrich, USA) by following the method of (Law and Slepecky, 1961), the quantity of PHB produced by different bacterial isolates was determined.

Determination of Indole Acetic acid (IAA) production and phosphate solubilization by Pseudomonas spp.

For the quantitative estimation of IAA, active culture of Pseudomonas spp. were inoculated to $20 \mathrm{ml} \mathrm{DF}$ salts minimal media (Dworkin and Foster 1958) in $100 \mathrm{ml}$ conical flasks and incubated for 3 days at $28^{\circ} \mathrm{C}$. The medium was supplemented with L-tryptophan at a concentration of $1.02 \mathrm{~g} / \mathrm{l}$. After incubation for $72 \mathrm{~h}$, the grown bacterial cells were removed from the culture medium by centrifugation at $5,000 \mathrm{rpm}$ for $5 \mathrm{~min}$ and the $\mathrm{pH}$ of the medium of all isolates was recorded. One $\mathrm{ml}$ aliquot of the supernatant was mixed vigorously with $4 \mathrm{ml}$ of Salkowski's reagent (Gordon and Weber 1951) and allowed to stand at room temperature for $20 \mathrm{~min}$. The absorbance at $535 \mathrm{\eta m}$ was measured with DF salts minimal media (plus Salkowski's reagent) as blank. The concentration of IAA in each culture supernatant was determined using an IAA (Himedia) standard curve.

Screening of phosphate solubilisation ability and its quantitative estimation

Qualitative screening of phosphate solubilising fluorescent Pseudomonas was performed on Pikovskaya agar medium 
(Himedia) containing tricalcium phosphate as a phosphate source and bromocresol purple $(0.1 \mathrm{~g} / \mathrm{l})$ as a $\mathrm{pH}$ indicator for acidification(Vazquez et al., 2000). After incubation of fresh cultures of fluorescent Pseudomonas at $28 \pm 2$ _C for $48 \mathrm{~h}$, phosphate solubilizing isolates turned the media color from purple to yellow in the zones of acidification.

Quantitative estimation of phosphate solubilisation in Pikovskaya broth (Himedia) was performed according to the procedure of (Murphy and Riley 1962). Fresh cultures of fluorescent Pseudomonas isolates were inoculated to $50 \mathrm{ml}$ of Pikovskaya's broth and incubated at $28 \pm 2 \_\mathrm{C}$ and $100 \mathrm{rpm}$. The amount of inorganic phosphate $(\mathrm{Pi})$ released in the broth was estimated after 7 days of incubation in comparison with un-inoculated control.

The broth culture was centrifuged at 10,000 rpm for $10 \mathrm{~min}$ to separate the supernatant from the bacterial growth and insoluble phosphate. To the $0.5 \mathrm{ml}$ of the culture supernatant $5 \mathrm{ml}$ of chloromolybdic acid was added and mixed thoroughly.

Volume was made up to $10 \mathrm{ml}$ with distilled water and $125 \mathrm{ll}$ of chlorostannous acid was added to it. Immediately, the final volume was made up to $25 \mathrm{ml}$ with distilled water and mixed thoroughly. After $15 \mathrm{~min}$, the blue color developed was read in a spectrophotometer at $610 \mathrm{~nm}$ using a reagent blank.

Corresponding amount of soluble phosphorous was calculated from standard curve of potassium dihydrogen phosphate (KH2PO4). Phosphate solubilizing activity was expressed in terms of tricalcium phosphate solubilization which in turn was measured by $\mathrm{lg} / \mathrm{ml}$ of available orthophosphate as calibrated from the standard curve of $\mathrm{KH} 2 \mathrm{PO} 4$.

\section{Results and Discussion}

Quantification of Indole acetic acid (IAA) production by Pseudomonas spp.

Production of IAA and IAA related compounds was evaluated for twenty four isolates of fluorescent Pseudomonas spp. in DF salt culture medium amended with 1.02 $\mathrm{g} / \mathrm{L}$ from $5 \mathrm{mM}$ stock of L-tryptophan as precursor molecule and any IAA precursor molecule as control. The mixture of culture supernatant and Salkowski's reagent was incubated at room temperature for $20 \mathrm{~min}$ and the absorbance was measured at $535 \mathrm{\eta m}$. The concentration of IAA and IAA related compounds was evaluated by comparison with a standard curve prepared using serial dilutions $(0-100 \mu \mathrm{g} / \mathrm{ml})$ prepared from commercially available IAA. Interpolation of the colorimeter readings with standard curve were used to quantify the amount of IAA produced by different isolates of Pseudomonas in the media which ranged from 8.09 to $63.18 \mu \mathrm{g} / \mathrm{ml}$ (Table 1 ).

Twenty four fluorescent Pseudomonas isolates produced varying proportions of IAA from Ltryptophan as a precursor. Fluorescent Pseudomonas isolates P124, P99, P72and P201 secreated high proportions of IAA in the supernatents. Maximum amount of IAA production was observed with isolate P124 $(63.18 \mu \mathrm{g} / \mathrm{ml})$ whereas isolate P6 $(8.09 \mu \mathrm{g} / \mathrm{ml})$ was the lowest producer (Table 1). Three groups of IAA producers could be resolved after interpolation of the colorimeter readings with standard curve were used to quantify the amount of IAA secreted by different isolates of Pseudomonas in the media: Low IAA secreting fluorescent Pseudomonas isolates (8.09 to 9.91 $(\mu \mathrm{g} / \mathrm{ml})$ ) were P6 P233 P85 P167 and P216; Medium IAA secreting fluorescent Pseudomonas isolates (10.27 to $16.18(\mu \mathrm{g} / \mathrm{ml}))$ were P141, P76, P176, P143, P247, P179, $\mathrm{P} 11, \mathrm{P} 151, \mathrm{P} 126, \mathrm{P} 67, \mathrm{P} 248, \mathrm{P} 5, \mathrm{P} 161)$ and 
High IAA secreting fluorescent Pseudomonas isolates (21 to $63(\mu \mathrm{g} / \mathrm{ml}))$ were P129, P205, P201, P72, P99, P124 (Table 1).

Several PGPRs as well as some pathogenic, symbiotic and free living rhizobacterial species are reported to produce IAA and gibberllic acid in the rhizospheric soil and thereby plays a significant role in increasing the root surface area and number of root tips in many plants (Han et al., 2005). Recent investigations on auxin synthesizing rhizobacteria (Spaepen et al., 2007) as phytohormone producer demonstrated that the rhizobacteria can synthesize IAA from tryptophan by different pathways, although the general mechanism of auxin synthesis was basically concentrated on the tryptophanindependent pathways. The phytopathogenic bacteria rather use the indole acetamide pathway to synthesize IAA that has been implicated earlier in the tumor induction in plants. (Swain et al., 2007) reported a positive effect of IAA producing strains of Bacillus subtilis on Dioscorea rotundata L. They applied a suspension of B. subtilis on the surface of the plant, which resulted in an increase in the root: stem ratio as well as number of sprouts as compared with the noninoculated plants. Potentiality of Azotobacter spp., to produce high amount of IAA (7.3$32.8 \mathrm{mg} / \mathrm{ml}$ ) in agriculture was reported by (Ahmad et al., 2005). Laboratory studies have emphasized on use of plant growth promoting rhizobacteria (PGPR) as biocontrol agents (Hossain et al., 2007) and the role of auxin (IAA) in plant growth promotion (ContrerasCornejo et al., 2009). Fluorescent Pseudomonas are one of the most abundant bacteria in the rhizosphere of many plants (Freitas and Germida 1990; Botelho and Mendonça-Hagler 2006), have large capacity to produce phytohormones, mainly auxins (Patten and Glick 1996; Patten and Glick 2002a; Patten and Glick 2002b; Khalid et al., 2005) and secondary metabolites, such as antibiotics (Bergsma-Vlami et al., 2005), thus they are able to improve plant growth and plant health (Glick 1995; Belimov et al., 2007; Belimov et al., 2009a; Belimov et al., 2009b).

\section{Screening of phosphate solubilizing Pseudomonas spp. and its quantification}

Phosphorus frequently is the least accessible macronutrient in many ecosystems and its low availability is often limiting to plant growth (Raghothama, 1999). All the 24 isolates were capable of differentially utilizing tri-calcium phosphate in both agar plate and broth assays. By preparing standard curve the amount of inorganic phosphate solubilized by different Pseudomonas isolates were estimated wavelength $610 \eta \mathrm{m}$. Screening of isolates showed variation in their ability to utilized calcium phosphate supplemented in different nutrient constituents. Qualitative and Quantitative estimation of phosphate solubilization, carried out after incubation of 7 days at $28 \pm 2{ }^{\circ} \mathrm{C}$ is presented in (Table 1). In vitro phosphate solubilization efficacy of fluorescent Pseudomonas spp. isolates as performed on Pikovskaya's agar by acidification showed positive results for all the 24 isolates tested.

Quantitative estimation of soluble phosphate concentrations in Pikovskaya's broth was expressed as $\mu \mathrm{g} / \mathrm{ml}$ and it varied significantly from 88 to $768 \mu \mathrm{g} / \mathrm{ml}$.

Isolate P216 can be considered as promising inducer of phosphate mobilization. The amount of inorganic phosphate solubilized was $768 \mu \mathrm{g} / \mathrm{ml}$ followed by isolates P67, P201 P72 P76 and P161solubilizing $550 \mu \mathrm{g} / \mathrm{ml}, 518$ $\mu \mathrm{g} / \mathrm{ml}$ and $502 \mu \mathrm{g} / \mathrm{ml}, 484 \mu \mathrm{g} / \mathrm{ml}, 455 \mu \mathrm{g} / \mathrm{ml}$ phosphate. Among 24 isolates screened these were the best phosphate solubilizers (Table 1).

These candidate isolates can be used as microbial inoculants to improve soil fertility 
by releasing bound phosphorus thereby increasing the crop yield potential. Stimulation of different crops by plant growth promoting Pseudomonas isolates with potential phosphate solubilization ability may help in exploiting large reserves of phosphorus present in most agricultural soils. Several Pseudomonas species have been reported among the most efficient phosphatesolublizing bacteria and as important bioinoculants due to their multiple biofertilizing activities of improving soil nutrient status, secretion of plant growth regulators and suppression of soil-borne pathogens (Rodríguez and Fraga 1999; Gulati et al., 2008; Agrawal et al., 2015).

\section{Screening of polyhydroxybutyrate (PHB) producers and its quantification}

Biodegradable and biocompatible polyesters such as polyhydroxyalkanoates (PHA) have potential pharmaceutical values (Takahashi et al., 1994). In an alkaline environment Pseudomonas has been reported to produce medium-chain-length (R)-3-hydroxy alkanoates (Wang et al., 2007). In the present investigation all the 24 fluorescent Pseudomonas spp. isolates gave positive result for PHB accumulation in Sudan Black B qualitatively screening test in $1 \%$ glucose supplemented nutrient agar medium. (Madison and Huisman, 1999) have also reported that these biopolymers are accumulated as inclusions (PHA granules) in the bacterial cytoplasm in response to inorganic nutrient limitations, generally, when the microbes are cultured in the presence of an excess carbon source.

However, in present study there was significant difference in quantitative analysis of all the isolates which ranged from 2.67 to $15.74 \mathrm{mg} / \mathrm{ml}$. The lowest observed value was for isolate P6 $(2.67 \mathrm{mg} / \mathrm{ml})$ and the highest was for isolate P126 $(15.74 \mathrm{mg} / \mathrm{ml})$.
Isolates P99, P161, P233, P151 and P179 also produced significantly higher amounts of PHB (i.e $15.31 \mathrm{mg} / \mathrm{ml}, 14.52 \mathrm{mg} / \mathrm{ml}, 14.40 \mathrm{mg} / \mathrm{ml}$ and $14.25 \mathrm{mg} / \mathrm{ml}$ and $14.05 \mathrm{mg} / \mathrm{ml}$ respectively) as compared to other isolates (Table 1).

Two catagories of PHB producers were resolved after 24 fluorescent Pseudomonas spp. isolates gave positive result for PHB accumulation in Sudan Black B qualitatively screening test in $1 \%$ glucose supplemented nutrient agar medium PHB production 2.67 to 8.99 (mg/ml) P6, P11, P5, P201, P67, P124, P85; PHB production 10.48 to $15.75(\mathrm{mg} / \mathrm{ml})$ P143, P141, P205, P216, P167, P247, P76, P72, P248, P129, P176, P179, P151, P233, P161, P99, P126

Apart from primary and secondary metabolite production, certain fluorescent Pseudomonads (especially $P$. putida) are suitable as wholecell biocatalyzers for the production of several value-added industrial compounds such as biodegradable and biocompatible polyesters called polyhydroxyalkanoates (PHA) or polyhydroxybutyrates (PHB). It accumulates as discrete granules and is used as storage material for carbon and for reducing equivalents by $P$. putida. This property has been widely exploited for their targeted biosynthesis in this organism(Hoffmann and Rehm, 2004). Different strains of $P$. putida such as $P$. putida KT2440, $P$. putida GPo1, $P$. putida $\mathrm{S} 12$, etc. have been investigated for its capacity to accumulate PHAs and PHBs from different carbon sources (Durner et al., 2001; Hartmann et al., 2004; Meijnen et al., 2008). The pha gene cluster is responsible for the accumulation of PHAs and PHBs in P. putida (Vo et al., 2008; Chung et al., 2009; Wang and Nomura 2010). Expenditures for largescale production of PHA were almost evenly divided between carbon source, fermentation process and separation process (Sun et al., 2007; Elbahloul and Steinbüchel 2009). 
Therefore, screening for carbohydrate utilization by Pseudomonas isolate may help in identifying candidate isolate which dwells upon cheaper carbon sources. Our work reports that all the 24 fluorescent Pseudomonas isolates utilized relatively cheaper carbohydrates such as xylose, dextrose, galactose, melibiose, and mannose corroborates earlier reports by Agrawal et al., (2015).

Plant growth promoting response of rice, wheat, greengram, blackgram, lathyrus, chickpea, bottle gourd following seed bacterization with fluorescent Pseudomonas isolates

Indole acetic acid affects the physiology of plants in dramatically different ways which is a well know fact. Plant responses to IAA vary from plant to plant tissue involved (roots, shoots, the optimal level of IAA for supporting plant growth is $\sim 5$ orders of magnitude lower for roots than for shoots); and as a function of the developmental stage of the plant. However, the endogenous pool of plant IAA may be suboptimal or optimal (Pilet and Saugy 1987) may be altered by the acquisition of IAA that has been secreted by soil bacteria and is important in determining whether bacterial IAA stimulates or suppresses plant growth. Microbial IAA could be involved in the growth stimulation observed in our greenhouse assay. Production of plant growth regulators by the microorganisms is another important mechanism often associated with growth stimulation (Vessey, 2003). The balance between vegetative and reproductive growth is controlled by hormone signaling within the plant and therefore be highly influenced by it (Taiz and Zeiger, 1991). At relatively high concentrations, natural auxins, such as IAA, stimulate shoot elongation and root induction while reducing root elongation (Tanimoto, 2005; Gravel et al., 2007) in his results, reported that $P$. putida subgroup B strain 1 and $T$. atroviride have the ability to synthesize IAA from different precursors in vitro, which supports the theory that microbial IAA could be involved in the growth stimulation observed in our greenhouse assay In the present investigation we tried to correlate the siderophore producing ability and Indole acetic acid (IAA), PHB production and inorganic phosphate solubilization ability of Fluorescent Pseudomonas with plant growth promoting ability. It was observed that a group of fluorescent Pseudomonas isolates induced significant growth effects on root and shoot on different crop plants, some only induce significant growth effects on shoot and or only root. Rice (Oryza sativa var. swarna): Efficacy of different isolates of Pseudomonas for rice plants varied to induce root and shoot length ranging from 7.15 to $16.00 \mathrm{~cm}$ and 19.03 to $24.95 \mathrm{~cm}$ respectively. Maximum root length $(16 \mathrm{~cm})$ and shoot length $(24.95 \mathrm{~cm})$ were recorded when seeds were treated with P247 and P176 respectively (Table 7). Seed treated with isolate P247 has $6.67 \mathrm{~cm}(41.69 \%)$ more root length and isolate P176 has $4.03 \mathrm{~cm}$ $(16.56 \%)$ shoot length as compared to control. Seven isolates were able to exert plant growth promoting activity on rice. Isolates P151, P233 significantly increased the root and shoot growth of rice. Isolates P85, P176, P216 significantly increased the shoot growth of rice. Isolates P67 and P247 significantly increased the root growth of rice. Wheat (Triticum aestivum var. GW-272): Efficacy of different isolates of Pseudomonas for wheat plants varied to induce root and shoot length ranging from 24.38 to $36.52 \mathrm{~cm}$ and 30.77 to $39.78 \mathrm{~cm}$ respectively. Maximum root length $(36.52 \mathrm{~cm})$ and shoot length $(39.78 \mathrm{~cm})$ were recorded when seeds were treated with P124 and P141 respectively as compared to control (Table 7). Seed treated with isolate P124 has $6.32 \mathrm{~cm}(17.30 \%)$ more root length and isolate P141 has $8.05 \mathrm{~cm}(20.23 \%)$ shoot length as compared to control. Twenty one isolates were 
able to exert plant growth promoting activity on wheat. Isolates P124 significantly increased the root and shoot growth of wheat. Isolates P67, P72, P76, P85, P99, P126, P129, P141, P143, P151, P161, P167, P176, P179, P201, P205, P216, P233, P247 and P248 significantly increased the shoot growth. Bottlegourd (Lagenaria siceraria): The screening of Pseudomonas spp. treated seed of bottle gourd was evaluated 40 days after sowing. The efficacy of different species of Pseudomonas isolates varied to induce root length ranged from 20.33 to $112.73 \mathrm{~cm}$ for which P248 $(112.73 \mathrm{~cm})$ isolate measured longest root length and $\mathrm{P} 151(20.33 \mathrm{~cm})$ isolate shortest root length (Table 8). The shoot length measured ranged from 3.95 to $63.75 \mathrm{~cm}$ for which fluorescent Pseudomonas spp. isolate P167 $(63.75 \mathrm{~cm})$ measured longest shoot length and P126 $(3.95 \mathrm{~cm})$ isolate measured shortest shoot length).

Seed treated with isolate P248 has $61.05 \mathrm{~cm}$ $(68.83 \%)$ more root length and isolate P167 has $46.15 \mathrm{~cm}(72.39 \%)$ shoot length as compared to control Thirteen isolates were able to exert plant growth promoting activity on bottle gourd. Seed biopriming of bottlegourd seeds with isolate P76, P99, P124 and P167increased the root and shoot length whereas biopriming with isolates P85, P126, P143, P176, P248 resulted only increase in shoot length. Seed biopriming of bottlegourd seeds with P72, P129, P141 and P151 increased the root length. Lathyrus (Lathyrus sativus var. KH-014): Efficacy of different isolates of Pseudomonas for lathyrus plants varied to induce root and shoot length ranging from 12.79 to $25.70 \mathrm{~cm}$ and 13.12 to $20.82 \mathrm{~cm}$ respectively. Maximum root length $(25.7 \mathrm{~cm})$ and shoot length $(20.815 \mathrm{~cm})$ were recorded when seeds were treated with P216 and P85 respectively (Table 8). Seed treated with isolate P216 has $7.51 \mathrm{~cm}(29.22 \%)$ more root length and isolate P85 has $7.45 \mathrm{~cm}(35.78 \%)$ shoot length as compared to control.
Seventeen isolates were able to exert plant growth promoting activity on Lathyrus except P216 all the sixteen isolates (P5, P6, P72, P85, P99, P11, P124, P126, P129, P151, P167, P176, P201, P205, P247, P248) significantly promoted the shoot growth of lathyrus. Chickpea (Cicer arientinum): Efficacy of different isolates of Pseudomonas for chickpea plants varied to induce root and shoot length ranging from 16.75 to $38.85 \mathrm{~cm}$ and14.933 to $25.7 \mathrm{~cm}$ respectively. Maximum root length $(38.85 \mathrm{~cm})$ and shoot length $(25.7$ $\mathrm{cm})$ were recorded when seeds were treated with P72 as compared to control (Table 8). Seed treated with isolate P72 had $10.52 \mathrm{~cm}$ $(27.08 \%)$ and $9.37 \mathrm{~cm}(36.45 \%)$ more root and shoot length respectively as compared to control. Twenty isolates were able to exert plant growth promoting activity on chickpea. Isolate P72 significantly increase the root and shooth growth of chickpea whereas nineteen isolates P67, P76, P85, P99, P11, P124, P126, P129, P141, P143, P151, P161, P176, P201, P205, P216, P233, P247 significantly increase the shoot growth of chickpea. Greengram (Vigna radiata var. puspa vishal): Efficacy of different isolates of Pseudomonas for greengram plants varied to induce root and shoot length ranging from 13.99 to $22.15 \mathrm{~cm}$ and 13.7 to $20.385 \mathrm{~cm}$ respectively. Maximum root length $(19.59 \mathrm{~cm})$ and shoot length $(20.39$ $\mathrm{cm})$ were recorded when seeds were treated with P151 and P11 respectively (Table 9). Seed treated with isolate $\mathrm{P} 11$ has $6.61 \mathrm{~cm}$ (32.81\%) more shoot length as compared to control. Isolates P6, P67, P99, P11, P124, P129, P143, P151, P167, P176, P201, P216, $\mathrm{P} 233$ and $\mathrm{P} 247$ on biopriming greengram seeds promoted shoot growth whereas P141 promoted only increased root and shoot development. Blackgram (Vigna mungo var. T-U-94-2): Efficacy of different isolates of Pseudomonas for blackgram plants varied to induce root and shoot length ranging from 14.59 to $24.83 \mathrm{~cm}$ and 12.34 to $18.62 \mathrm{~cm}$ respectively. 
Table.1 Spectrophotometric determination of Indole acetic acid (IAA), PHB production and inorganic phosphate solubilization in different proportions by fluorescent Pseudomonas isolates

\begin{tabular}{|c|c|c|c|c|c|c|}
\hline \multirow[t]{3}{*}{ S. No. } & \multirow[t]{3}{*}{ Isolates } & \multirow[t]{3}{*}{$\begin{array}{l}\text { IAA production } \\
\qquad(\mu \mathrm{g} / \mathrm{ml})\end{array}$} & \multirow[t]{3}{*}{$\begin{array}{l}\text { PHB Production } \\
\text { (mg/ml) }\end{array}$} & \multicolumn{3}{|c|}{$\begin{array}{c}\text { Phosphate solubilization in } \\
\text { Pikovskaya's }\end{array}$} \\
\hline & & & & \multirow{2}{*}{$\begin{array}{l}\text { Broth } \\
(\mu \mathrm{g} / \mathrm{ml})\end{array}$} & \multicolumn{2}{|c|}{ Agar medium } \\
\hline & & & & & with $\mathrm{BCP}$ & without BCP \\
\hline 1 & P6 & 8.09 & 2.67 & 264 & ++ & ++ \\
\hline 2 & P11 & 13.36 & 5.37 & 407 & + & ++ \\
\hline 3 & P5 & 15.36 & 6.86 & 379 & ++ & + \\
\hline 4 & P201 & 22.27 & 6.86 & 518 & ++ & + \\
\hline 5 & P67 & 13.91 & 7.56 & 550 & +++ & +++ \\
\hline 6 & P124 & 63.18 & 7.82 & 356 & +++ & +++ \\
\hline 7 & P85 & 9.09 & 8.99 & 399 & + & +++ \\
\hline 8 & $\mathrm{P} 143$ & 12.55 & 10.48 & 135 & ++ & + \\
\hline 9 & P141 & 10.27 & 11.55 & 383 & +++ & ++ \\
\hline 10 & P205 & 21.91 & 11.83 & 347 & ++ & + \\
\hline 11 & P216 & 9.91 & 11.93 & 768 & +++ & +++ \\
\hline 12 & P167 & 9.64 & 11.97 & 95 & ++ & + \\
\hline 13 & P247 & 13 & 12.52 & 278 & ++ & ++ \\
\hline 14 & P76 & 11.09 & 12.91 & 484 & + & ++ \\
\hline 15 & P72 & 24 & 13.19 & 502 & + & + \\
\hline 16 & P248 & 14.36 & 13.24 & 335 & + & + \\
\hline 17 & P129 & 21 & 13.4 & 306 & ++ & ++ \\
\hline 18 & P176 & 12.36 & 13.9 & 194 & + & ++ \\
\hline 19 & P179 & 13.27 & 14.05 & 239 & ++ & ++ \\
\hline 20 & $\mathrm{P} 151$ & 13.45 & 14.25 & 88 & + & + \\
\hline 21 & P233 & 8.82 & 14.4 & 139 & ++ & ++ \\
\hline 22 & P161 & 16.18 & 14.52 & 455 & + & + \\
\hline 23 & P99 & 27.09 & 15.31 & 401 & +++ & +++ \\
\hline 24 & P126 & 13.64 & 15.74 & 365 & + & + \\
\hline Max. & & 63.18 & 15.74 & 768 & & \\
\hline Min. & & 8.09 & 2.67 & 88 & & \\
\hline Control & & & & 84 & & \\
\hline
\end{tabular}

+++: luxuriant/high phosphate solubilization; ++: medium phosphate solubilization; +: low phosphate solubilization; -: no phosphate solubilization. 
Int.J.Curr.Microbiol.App.Sci (2018) 7(2): 3511-3532

Table.2 Fluorescent Pseudomonas isolates influencing root length in different crop plants

\begin{tabular}{|c|c|c|c|c|c|c|c|}
\hline \multirow{2}{*}{ Treatment } & \multicolumn{7}{|c|}{ Root length (cm) } \\
\hline & Blackgram & Bottlegourd & Chickpea & Greengram & Lathyrus & Rice & Wheat \\
\hline C & $16.435 \mathrm{ef} \pm 0.733$ & $43.9 \mathrm{efg} \pm 12.27$ & $28.333 \mathrm{bcdef} \pm 0.726$ & $617.28 \mathrm{bcde} \pm 2.10$ & 018.185 bcdefg \pm 0.679 & $9.325 \mathrm{efg} \pm 1.135$ & $30.2 b c d e f g \pm 0.742$ \\
\hline P5 & $18.565 \mathrm{bcdef} \pm 1.115$ & $5 \quad 45.7 \mathrm{defg} \pm 6.74$ & $29 \mathrm{bcdef} \pm 6.449$ & $15.39 \mathrm{de} \pm 2.58$ & 20.565 abcde \pm 0.957 & $12.2 \mathrm{abcdef} \pm 1.301$ & 28.42 defgh \pm 1.369 \\
\hline P6 & $20.985 \mathrm{abcd} \pm 1.401$ & 42.83efgh \pm 0.82 & $20.533 \mathrm{fg} \pm 0.088$ & $18.04 \mathrm{bcd} \pm 1.80$ & $19.415 \mathrm{abcde} \pm 0.853$ & 10.25 cdefg \pm 0.487 & $27.68 \mathrm{efgh} \pm 1.685$ \\
\hline P67 & $20.215 \mathrm{bcde} \pm 1.540$ & $54 \mathrm{cdefg} \pm 8.01$ & 27.333 cdef \pm 1.202 & $14.72 \mathrm{de} \pm 0.48$ & 19.385 bcdef \pm 2.496 & $14.5 \mathrm{ab} \pm 2.480$ & $27.24 \mathrm{fgh} \pm 1.259$ \\
\hline P72 & $20.225 \mathrm{bcde} \pm 2.244$ & $83.3 b \pm 1.15$ & $38.85 \mathrm{a} \pm 6.438$ & $17.47 \mathrm{bcde} \pm 1.12$ & 219.085 bcdef \pm 1.464 & $10 \mathrm{defg} \pm 0.970$ & $27.56 \mathrm{fgh} \pm 1.755$ \\
\hline P76 & $19.15 \mathrm{bcde} \pm 1.187$ & $70.3 b c \pm 2.77$ & $36.833 \mathrm{ab} \pm 2.920$ & $13.99 \mathrm{e} \pm 2.29$ & $12.785 \mathrm{~g} \pm 0.585$ & $8.525 f g \pm 0.581$ & $30.66 \mathrm{bcdefg} \pm 0.897$ \\
\hline P85 & $20.665 \mathrm{abcde} \pm 0.95$ & 941.83 fgh \pm 12.44 & 28.833 bcdef \pm 0.833 & $316.22 \mathrm{cde} \pm 0.68$ & 18.285 bcdef \pm 2.483 & $12.175 \mathrm{abcdef} \pm 1.035$ & $27.19 \mathrm{gh} \pm 1.119$ \\
\hline P99 & $19.765 \mathrm{bcde} \pm 0.251$ & $70.8 b c \pm 2.64$ & $34.166 a b c \pm 2.351$ & $15.82 \mathrm{cde} \pm 1.29$ & $22.35 \mathrm{ab} \pm 3.126$ & $9.2 \mathrm{efg} \pm 0.426$ & $27.69 \mathrm{efgh} \pm 1.102$ \\
\hline P11 & $19.925 \mathrm{bcde} \pm 1.858$ & 44.5 efg \pm 6.01 & $29.833 \mathrm{bcde} \pm 0.441$ & $18.03 \mathrm{bcd} \pm 0.44$ & $22.575 \mathrm{ab} \pm 1.424$ & $8.5 \mathrm{fg} \pm 0.951$ & $31.86 \mathrm{bcdef} \pm 1.999$ \\
\hline P124 & $18.635 \mathrm{bcdef} \pm 0.88$ & $87.7 \mathrm{~b} \pm 7.23$ & $26.833 \mathrm{cdef} \pm 4.086$ & $17.95 \mathrm{bcd} \pm 0.77$ & $21.375 \mathrm{abcd} \pm 3.196$ & 10.3 cdefg \pm 2.358 & $36.52 \mathrm{a} \pm 2.766$ \\
\hline P126 & $17.425 \mathrm{def} \pm 0.574$ & $64.95 \mathrm{bcdef} \pm 8.54$ & $23 \mathrm{defg} \pm 2.021$ & $15.99 \mathrm{cde} \pm 1.49$ & $16.375 \mathrm{defg} \pm 1.830$ & $9.775 \mathrm{efg} \pm 0.559$ & $30.07 \mathrm{bcdefg} \pm 1.316$ \\
\hline P129 & $19.715 \mathrm{bcde} \pm 1.178$ & $69.88 b c \pm 9.66$ & 27.666 cdef \pm 0.882 & $15.69 \mathrm{cde} \pm 2.80$ & $16.465 \operatorname{defg} \pm 1.723$ & $10.825 \mathrm{bcdefg} \pm 0.409$ & 28.12efgh \pm 1.907 \\
\hline P141 & $19.65 \mathrm{bcde} \pm 0.991$ & $67.83 \mathrm{bcd} \pm 11.11$ & $133.166 a b c \pm 2.242$ & $22.15 a \pm 0.76$ & $15.665 \mathrm{efg} \pm 2.070$ & $7.15 \mathrm{~g} \pm 0.891$ & $26.56 \mathrm{gh} \pm 1.240$ \\
\hline P143 & $22.135 \mathrm{abc} \pm 2.148$ & $59.18 \mathrm{cdefg} \pm 4.64$ & $433.65 \mathrm{abc} \pm 3.839$ & $18.49 \mathrm{abcd} \pm 0.84$ & 417.55 bcdefg \pm 0.484 & $7.625 \mathrm{~g} \pm 1.004$ & $31.14 \mathrm{bcdefg} \pm 1.775$ \\
\hline P151 & $16.465 \mathrm{ef} \pm 0.802$ & $75.63 b c \pm 6.82$ & $31.433 \mathrm{abcd} \pm 2.599$ & $19.59 \mathrm{abc} \pm 1.48$ & $13.965 \mathrm{fg} \pm 0.380$ & $13.625 \mathrm{abcd} \pm 2.755$ & $30.86 \mathrm{bcdefg} \pm 1.150$ \\
\hline P161 & $16.785 \mathrm{def} \pm 1.574$ & $42.4 \mathrm{efgh} \pm 9.24$ & $30.5 \mathrm{abcde} \pm 2.180$ & $15.94 \mathrm{cde} \pm 0.38$ & $15.775 \mathrm{efg} \pm 1.730$ & $12.5 \mathrm{abcde} \pm 0.631$ & 32.28 abcde \pm 1.513 \\
\hline P167 & $17.835 \mathrm{def} \pm 1.218$ & $73.5 b c \pm 16.98$ & $22 \mathrm{efg} \pm 4.726$ & $18.63 \mathrm{abcd} \pm 1.27$ & $718.735 \mathrm{bcdef} \pm 0.671$ & $9.8 \mathrm{defg} \pm 0.715$ & $24.38 \mathrm{~h} \pm 1.906$ \\
\hline P176 & $22.7 \mathrm{ab} \pm 2.257$ & $65.6 \mathrm{bcde} \pm 10.00$ & $24.25 \mathrm{defg} \pm 3.320$ & $17.08 \mathrm{bcde} \pm 0.23$ & 320.525 abcde \pm 2.771 & $10 \mathrm{defg} \pm 1.772$ & $34.51 \mathrm{ab} \pm 1.602$ \\
\hline P179 & $17.75 \mathrm{def} \pm 2.027$ & $20.33 \mathrm{~h} \pm 1.13$ & $16.75 \mathrm{~g} \pm 1.299$ & $20.37 \mathrm{ab} \pm 0.17$ & 16.7 cdefg \pm 1.198 & $7.8 \mathrm{~g} \pm 0.356$ & 28.61defgh \pm 1.749 \\
\hline P201 & $19.885 \mathrm{bcde} \pm 1.499$ & $52.88 \mathrm{cdefg} \pm 7.83$ & 3 24.4defg \pm 3.114 & $16.47 \mathrm{bcde} \pm 1.08$ & $819.915 b c d e \pm 3.689$ & $8.625 f g \pm 2.138$ & $29.44 \mathrm{cdefg} \pm 1.610$ \\
\hline P205 & $16.95 \mathrm{def} \pm 1.551$ & 42.7efgh \pm 5.66 & $23.933 \mathrm{defg} \pm 0.788$ & $16.60 \mathrm{bcde} \pm 1.80$ & 018.615 bcdef \pm 0.742 & $7.55 \mathrm{~g} \pm 0.144$ & 29.75 cdefg \pm 1.447 \\
\hline P216 & $19.675 \mathrm{bcde} \pm 2.523$ & $60 \mathrm{cdefg} \pm 9.37$ & $29.866 \mathrm{bcde} \pm 4.332$ & $218.00 \mathrm{bcd} \pm 1.41$ & $25.7 \mathrm{a} \pm 2.957$ & $8.7 \mathrm{efg} \pm 1.079$ & $27.41 \mathrm{fgh} \pm 1.529$ \\
\hline P233 & $24.825 \mathrm{a} \pm 2.510$ & $41.58 \mathrm{gh} \pm 4.30$ & 28.666 bcdef \pm 0.441 & $117.84 \mathrm{bcde} \pm 1.07$ & $7 \quad 15.715 \mathrm{efg} \pm 1.047$ & $13.9 \mathrm{abc} \pm 2.200$ & $32.82 \mathrm{abcd} \pm 1.641$ \\
\hline $\mathbf{P} 247$ & $18.125 \mathrm{cdef} \pm 1.196$ & $44.5 \mathrm{efg} \pm 11.85$ & $31.4 \mathrm{abcd} \pm 2.358$ & $16.00 \mathrm{cde} \pm 0.97$ & 19.315 bcdef \pm 1.818 & $16 a \pm 1.567$ & $33.79 a b c \pm 3.066$ \\
\hline P248 & $14.585 \mathrm{f} \pm 0.716$ & $112.73 \mathrm{a} \pm 4.10$ & 26.033 cdef \pm 2.338 & $16.09 \mathrm{cde} \pm 1.12$ & $21.93 \mathrm{abc} \pm 2.049$ & $10 \mathrm{defg} \pm 0.799$ & 29.48 cdefg \pm 1.389 \\
\hline Max. & $24.825 \mathrm{a} \pm 2.510$ & $112.73 a \pm 4.10$ & $38.85 \mathrm{a} \pm 6.438$ & $22.15 \mathrm{a} \pm 0.76$ & $25.7 a \pm 2.957$ & $16 a \pm 1.567$ & $36.52 \mathrm{a} \pm 2.766$ \\
\hline Min. & $14.585 \mathrm{f} \pm 0.716$ & $20.33 \mathrm{~h} \pm 1.13$ & $16.75 \mathrm{~g} \pm 1.299$ & $13.99 \mathrm{e} \pm 2.29$ & $12.785 \mathrm{~g} \pm 0.585$ & $7.15 \mathrm{~g} \pm 0.891$ & $24.38 \mathrm{~h} \pm 1.906$ \\
\hline CD 0.01 & 5.7 & 30.907 & 11.443 & - & 7.243 & 5.077 & 6.165 \\
\hline CD 0.05 & 4.298 & 23.295 & 8.584 & 3.923 & 5.467 & 3.825 & 4.652 \\
\hline C V & 15.917 & 27.961 & 18.49 & 16.217 & 20.76 & 26.234 & 12.461 \\
\hline F.cal & 2.115 & 5.559 & 2.835 & 1.688 & 2.274 & 2.987 & 2.814 \\
\hline
\end{tabular}


Table.3 Fluorescent Pseudomonas isolates influencing shoot length in different crop plants

\begin{tabular}{|c|c|c|c|c|c|c|c|}
\hline \multirow{2}{*}{$\begin{array}{l}\text { Isolate } \\
\quad \#\end{array}$} & \multicolumn{7}{|c|}{ Shoot length $(\mathrm{cm})$} \\
\hline & Blackgram & Bottlegourd & Chickpea & Greengram & Lathyrus & Rice & Wheat \\
\hline C & $12.625 \mathrm{mnop} \pm 0.3637$ & 17.6efgh \pm 1.254 & $16.333 \mathrm{mn} \pm 0.498$ & $13.7 \mathrm{~h} \pm 1.747$ & $13.365 \mathrm{i} \pm 1.094$ & 20.3hijk \pm 1.498 & $31.73 \mathrm{jk} \pm 0.4107$ \\
\hline P5 & $15.815 \mathrm{defgh} \pm 0.3044$ & 14.33 fgh \pm 0.794 & $14.933 n \pm 0.536$ & 14.665 fgh \pm 0.830 & $\begin{array}{c}16.635 \text { cdefg } \pm 0.83 \\
5\end{array}$ & 20.775ghijk \pm 0.771 & $33.04 \mathrm{ij} \pm 0.6838$ \\
\hline P6 & $18.025 \mathrm{ab} \pm 0.5456$ & 16.4 efgh \pm 0.589 & $\begin{array}{c}21.066 \text { defghi } \pm 0.63 \\
6\end{array}$ & $18.225 \mathrm{abcd} \pm 1.19$ & $19.135 \mathrm{abc} \pm 0.382$ & 21.65 fghij \pm 1.713 & $30.77 \mathrm{k} \pm 1.0157$ \\
\hline P67 & $\begin{array}{c}\text { 13.375jklmnop } \pm 0.74 \\
2\end{array}$ & 12.75 fgh \pm 0.777 & $21.5 \mathrm{cdefg} \pm 1.510$ & $\begin{array}{c}17.625 \mathrm{bcde} \pm 0.46 \\
8\end{array}$ & $13.885 \mathrm{hi} \pm 0.922$ & 23.225abcdefg \pm 0.390 & $36.04 \mathrm{efg} \pm 0.5142$ \\
\hline P72 & 13.165lmnop \pm 0.4625 & $15 \mathrm{fgh} \pm 1.780$ & $25.7 \mathrm{a} \pm 0.115$ & $16.1 \mathrm{defgh} \pm 1.022$ & $16.2 \mathrm{defgh} \pm 0.450$ & $19.25 \mathrm{jk} \pm 0.811$ & $36.35 \mathrm{defg} \pm 0.9332$ \\
\hline P76 & 14.575 hijk \pm 0.3172 & $36.73 b c d \pm 5.981$ & 21.266defgh \pm 0.50 & $14.8 \mathrm{fgh} \pm 0.452$ & $13.15 \mathrm{i} \pm 0.157$ & 21.85 efghi \pm 0.835 & $36.75 \mathrm{cdef} \pm 0.8353$ \\
\hline P85 & $16.8 \mathrm{bcde} \pm 0.3007$ & $40.68 b c \pm 7.366$ & $23.233 \mathrm{bcd} \pm 0.536$ & 14.985 fgh \pm 1.236 & $20.815 a \pm 0.780$ & $24.45 \mathrm{abcd} \pm 0.362$ & $\begin{array}{l}37.25 \mathrm{bcde} \pm 0.882 \\
5\end{array}$ \\
\hline P99 & $18.615 \mathrm{a} \pm 0.3912$ & $56.73 a \pm 5.496$ & $21.7 \mathrm{cdefg} \pm 0.751$ & $19.125 \mathrm{abc} \pm 0.859$ & $\begin{array}{c}\text { 17.765bcdef } \pm 0.67 \\
7\end{array}$ & 23.6abcdef \pm 0.942 & $38.84 a b \pm 0.4621$ \\
\hline P11 & $16 \mathrm{defg} \pm 0.3969$ & 11.1 fgh \pm 0.733 & $22.866 \mathrm{bcde} \pm 0.754$ & $20.385 a \pm 0.987$ & $19.835 \mathrm{ab} \pm 0.521$ & 21.225 fghijk \pm 0.684 & $33.78 \mathrm{hi} \pm 0.6555$ \\
\hline P124 & 15.235 fghi \pm 0.6759 & $58.93 a \pm 9.433$ & $23.833 \mathrm{abc} \pm 0.167$ & $\begin{array}{c}17.615 \mathrm{bcde} \pm 0.75 \\
0\end{array}$ & $20.2 \mathrm{ab} \pm 0.774$ & $\begin{array}{l}\text { 22.775abcdefgh } \pm 0.53 \\
6\end{array}$ & $\begin{array}{c}38.18 \mathrm{abcd} \pm 1.128 \\
9\end{array}$ \\
\hline P126 & 12.5 nор \pm 0.3048 & $50.65 \mathrm{ab} \pm 12.99$ & 20.75 efghi \pm 1.010 & 15.325 efgh \pm 0.820 & $18.1 \mathrm{bcde} \pm 0.174$ & 22.35 bcdefghi \pm 0.598 & $\begin{array}{c}36.89 \mathrm{bcdef} \pm 0.853 \\
8\end{array}$ \\
\hline P129 & $14.025 \mathrm{ijklm} \pm 0.4498$ & $24.53 \mathrm{def} \pm 4.514$ & $25.066 \mathrm{ab} \pm 0.924$ & $\begin{array}{c}16.865 \text { cdefg } \pm 1.17 \\
0\end{array}$ & $\begin{array}{c}18.015 \mathrm{bcde} \pm 0.92 \\
3\end{array}$ & $20.135 \mathrm{ijk} \pm 0.613$ & $38.55 \mathrm{abc} \pm 0.5677$ \\
\hline P141 & $17.515 \mathrm{abc} \pm 0.4502$ & $11.4 \mathrm{fgh} \pm 1.023$ & 18.933hijkl \pm 0.470 & $16.4 \mathrm{defg} \pm 0.524$ & 14.8ghi \pm 1.093 & 22.15 cdefghi \pm 0.366 & $39.78 \mathrm{a} \pm 0.9069$ \\
\hline P143 & $17.685 \mathrm{abc} \pm 0.4719$ & $37.4 \mathrm{bcd} \pm 3.447$ & 21 defghi \pm 1.732 & $19.175 \mathrm{abc} \pm 1.301$ & 15.285 fghi \pm 0.739 & $19.025 \mathrm{k} \pm 1.424$ & $35.9 \mathrm{efg} \pm 0.2994$ \\
\hline P151 & $12.335 \mathrm{op} \pm 0.4575$ & $20.85 \mathrm{efg} \pm 0.296$ & $\begin{array}{c}\text { 21.066defghi } \pm 0.58 \\
1\end{array}$ & $20.235 a \pm 1.473$ & $16.8 \mathrm{cdefg} \pm 1.365$ & $24.725 \mathrm{ab} \pm 0.201$ & $35.58 \mathrm{efgh} \pm 0.6486$ \\
\hline P161 & $\begin{array}{c}\text { 13.275klmnop } \pm 0.208 \\
7\end{array}$ & 12.58 fgh \pm 0.862 & $22.166 \mathrm{cdef} \pm 0.928$ & $16.185 \operatorname{defg} \pm 0.648$ & $13.115 \mathrm{i} \pm 0.984$ & 23.325abcdefg \pm 0.239 & 35.83 efg \pm 0.4839 \\
\hline P167 & $\begin{array}{c}\text { 13.885ijklmn } \pm 0.331 \\
9\end{array}$ & $63.75 a \pm 5.883$ & $16.8331 \mathrm{mn} \pm 0.899$ & $16.465 \mathrm{defg} \pm 0.390$ & $16.85 \mathrm{cdefg} \pm 1.646$ & 23.15 abcdefg \pm 0.744 & 34.45 ghi \pm 0.4381 \\
\hline P176 & $17.165 b c d \pm 0.6932$ & $37.5 \mathrm{bcd} \pm 11.76$ & 19.5 ghijk \pm 1.155 & $19.675 \mathrm{ab} \pm 0.338$ & $\begin{array}{c}18.785 \mathrm{abcd} \pm 1.57 \\
3\end{array}$ & $24.95 \mathrm{a} \pm 0.833$ & $\begin{array}{c}38.27 \mathrm{abcd} \pm 0.635 \\
0\end{array}$ \\
\hline P179 & $16.5 \mathrm{cdef} \pm 0.3857$ & $3.95 \mathrm{~h} \pm 0.466$ & $18.25 \mathrm{jklm} \pm 0.722$ & $\begin{array}{c}16.065 \text { defgh } \pm 0.22 \\
8\end{array}$ & $13.365 \mathrm{i} \pm 0.546$ & 22defghi \pm 0.082 & 36.09 efg \pm 0.3703 \\
\hline P201 & $16.75 \mathrm{bcde} \pm 0.4392$ & $15.4 \mathrm{fgh} \pm 1.362$ & 19.733ghijk \pm 0.536 & $16.935 \mathrm{cdef} \pm 0.388$ & 16.065 efgh \pm 0.933 & 21.4fghijk \pm 1.485 & $38.59 a b c \pm 0.9865$ \\
\hline P205 & $14.175 \mathrm{ijkl} \pm 0.3099$ & $\begin{array}{c}\text { 14.175fgh } \pm 0.31 \\
2\end{array}$ & 20.166fghij \pm 0.601 & $14.45 \mathrm{gh} \pm 0.149$ & $16.525 \mathrm{defg} \pm 0.545$ & $\begin{array}{c}22.325 \text { bcdefghi } \pm 0.72 \\
5\end{array}$ & 36.81 cdef \pm 0.3945 \\
\hline P216 & 14.7 ghij \pm 0.8147 & 11.55 fgh \pm 0.689 & 20.766 efghi \pm 0.865 & $16.965 \mathrm{cdef} \pm 0.889$ & 15.185fghi \pm 0.508 & $24.675 \mathrm{abc} \pm 1.071$ & $35.16 \mathrm{fgh} \pm 0.2973$ \\
\hline $\mathbf{P} 233$ & $15.585 \mathrm{efgh} \pm 0.8166$ & $\begin{array}{c}30.98 \mathrm{cde} \pm 12.05 \\
6\end{array}$ & $22.5 \mathrm{cdef} \pm 1.155$ & $\begin{array}{c}18.065 \mathrm{abcd} \pm 0.26 \\
8\end{array}$ & $14.65 \mathrm{ghi} \pm 0.899$ & $24.325 \mathrm{abcde} \pm 0.531$ & $35.86 \mathrm{efg} \pm 0.3638$ \\
\hline P247 & 15.7 efgh \pm 0.4449 & $7.14 \mathrm{gh} \pm 0.865$ & $18.733 \mathrm{ijkl} \pm 0.617$ & $16.65 \operatorname{defg} \pm 0.388$ & $19.825 \mathrm{ab} \pm 1.567$ & 22.3 bcdefghi \pm 1.219 & $\begin{array}{c}37.28 \mathrm{bcde} \pm 0.484 \\
7\end{array}$ \\
\hline P248 & $16.8 \mathrm{bcde} \pm 0.6334$ & $36.7 \mathrm{bcd} \pm 3.604$ & $17.366 \mathrm{klm} \pm 0.857$ & $15.2 \mathrm{efgh} \pm 0.228$ & $20.705 a \pm 0.755$ & 20.825 ghijk \pm 1.314 & $\begin{array}{c}38.12 \mathrm{abcd} \pm 0.595 \\
1\end{array}$ \\
\hline Max. & $18.615 a \pm 0.3912$ & $63.75 a \pm 5.883$ & $25.7 a \pm 0.115$ & $20.385 a \pm 0.987$ & $20.815 a \pm 0.780$ & $24.95 \mathrm{a} \pm 0.833$ & $39.78 \mathrm{a} \pm 0.9069$ \\
\hline Min. & $12.335 \mathrm{op} \pm 0.4575$ & $3.95 \mathrm{~h} \pm 0.466$ & $14.933 n \pm 0.536$ & 14.665 fgh \pm 0.830 & $13.115 \mathrm{i} \pm 0.984$ & $19.025 \mathrm{k} \pm 1.424$ & $30.77 \mathrm{k} \pm 1.0157$ \\
\hline $\begin{array}{l}\text { CD } \\
0.01\end{array}$ & 1.857 & 20.522 & 3.19 & 3.268 & 3.447 & 3.39 & 2.636 \\
\hline $\begin{array}{l}\text { CD } \\
0.05\end{array}$ & 1.401 & 15.464 & 2.391 & 2.464 & 2.59 & 2.568 & 1.987 \\
\hline $\mathrm{C} \mathrm{V}$ & 6.495 & 41.673 & 7.075 & 10.361 & 10.994 & 8.167 & 4.372 \\
\hline F.cal & 14.069 & 10.136 & 9.781 & 4.488 & 7.27 & 3.412 & 9.65 \\
\hline
\end{tabular}


Table.4 Fluorescent Pseudomonas isolates inducing significant increase in root and shoot length in different crop plants and their Indole acetic acid (IAA), PHB production and inorganic

phosphate solubilization ability

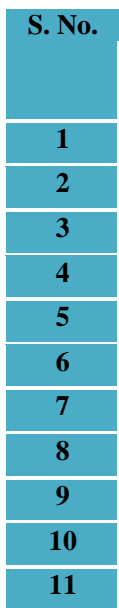

\begin{tabular}{|c|c|}
\hline Isolates & $\begin{array}{c}\text { Increase in root and shoot } \\
\text { growth }\end{array}$ \\
\hline P6 & $\begin{array}{c}\text { Blackgram } \\
\text { Chickpea }\end{array}$ \\
\hline P72 & Bottlegourd \\
\hline P76 & Bottlegourd \\
\hline P99 & Bottlegourd, Wheat \\
\hline P124 & Greengram \\
\hline P141 & Blackgram \\
\hline P143 & Rice \\
\hline P151 & Bottlegourd \\
\hline P167 & Blackgram \\
\hline P176 & Blackgram, Rice \\
\hline P233 & \\
\hline
\end{tabular}

\begin{tabular}{|c|c|}
\hline $\begin{array}{c}\text { IAA production } \\
(\boldsymbol{\mu g} / \mathbf{m l})\end{array}$ \\
\hline 8.09 \\
\hline 24 \\
\hline 11.09 \\
\hline 27.09 \\
\hline 63.18 \\
\hline 10.27 \\
\hline 12.55 \\
\hline 13.45 \\
\hline 9.64 \\
\hline 12.36 \\
\hline 8.82 \\
\hline
\end{tabular}

\begin{tabular}{|c|}
\hline $\begin{array}{c}\text { PHB Production } \\
(\mathrm{mg} / \mathrm{ml})\end{array}$ \\
\hline 2.67 \\
\hline 13.19 \\
\hline 12.91 \\
\hline 15.31 \\
\hline 7.82 \\
\hline 11.55 \\
\hline 10.48 \\
\hline 14.25 \\
\hline 11.97 \\
\hline 13.9 \\
\hline 14.4
\end{tabular}

\begin{tabular}{|c|c|c|}
\hline \multicolumn{3}{|c|}{ Phosphate solubilization in Pikovskaya's } \\
\hline $\begin{array}{c}\text { Broth } \\
(\mu \mathrm{g} / \mathrm{ml})\end{array}$ & with BCP & without BCP \\
\hline 264 & ++ & ++ \\
\hline 502 & + & + \\
\hline 484 & + & ++ \\
\hline 401 & +++ & +++ \\
\hline 356 & +++ & +++ \\
\hline 383 & +++ & ++ \\
\hline 135 & ++ & + \\
\hline 88 & + & + \\
\hline 95 & ++ & + \\
\hline 194 & + & ++ \\
\hline 139 & ++ & ++ \\
\hline
\end{tabular}

Table.5 Fluorescent Pseudomonas isolates inducing significant increase development of shoot length in different crop plants and their Indole acetic acid (IAA), PHB production and inorganic phosphate solubilization ability

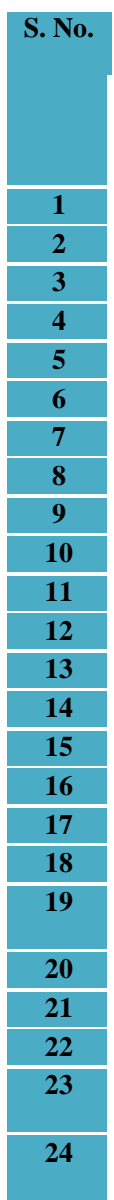

\begin{tabular}{|c|c|}
\hline Isolates & Increase in shoot growth \\
\hline P5 & Blackgram, Lathyrus \\
\hline P72 & Lathyrus, Wheat \\
\hline P161 & Chickpea, Wheat \\
\hline P179 & Blackgram, Wheat \\
\hline P6 & Chickpea, Greengram, Lathyrus \\
\hline P67 & Chickpea, Greengram, Wheat \\
\hline P76 & Blackgram, Chickpea, Wheat \\
\hline P141 & Blackgram, Chickpea, Wheat \\
\hline P167 & Greengram, Lathyrus, Wheat \\
\hline P233 & Chickpea, Greengram, Wheat \\
\hline P11 & Blackgram, Chickpea, Greengram, Lathyrus \\
\hline P124 & Blackgram, Chickpea, Greengram, Lathyrus \\
\hline P126 & Bottlegourd, Chickpea, Lathyrus, Wheat \\
\hline P129 & Chickpea, Greengram, Lathyrus, Wheat \\
\hline P143 & Bottlegourd, Chickpea, Greengram, Wheat \\
\hline P151 & Chickpea, Greengram, Lathyrus, Wheat; \\
\hline P205 & Blackgram, Chickpea, Lathyrus, Wheat; \\
\hline P248 & Blackgram, Bottlegourd, Lathyrus, Wheat \\
\hline P99 & $\begin{array}{l}\text { Blackgram, Chickpea, Greengram, Lathyrus, } \\
\text { Wheat; }\end{array}$ \\
\hline P201 & Blackgram, Chickpea, Greengram, Lathyrus, Wheat \\
\hline $\mathrm{P} 216$ & Blackgram, Chickpea, Greengram, Rice, Wheat \\
\hline $\mathrm{P} 247$ & Blackgram, Chickpea, Greengram, Lathyrus, Wheat \\
\hline P85 & $\begin{array}{l}\text { Blackgram, Bottlegourd, Chickpea, Lathyrus, Rice, } \\
\text { Wheat }\end{array}$ \\
\hline P176 & $\begin{array}{l}\text { Bottlegourd, Chickpea, Greengram, Lathyrus, Rice, } \\
\text { Wheat }\end{array}$ \\
\hline
\end{tabular}

\begin{tabular}{|c|c|}
\hline $\begin{array}{l}\text { IAA production } \\
\qquad(\mu \mathrm{g} / \mathrm{ml})\end{array}$ & $\begin{array}{l}\text { PHB Production } \\
(\mathrm{mg} / \mathrm{ml})\end{array}$ \\
\hline 15.36 & 6.86 \\
\hline 24 & 13.19 \\
\hline 16.18 & 14.52 \\
\hline 13.27 & 14.05 \\
\hline 8.09 & 2.67 \\
\hline 13.91 & 7.56 \\
\hline 11.09 & 12.91 \\
\hline 10.27 & 11.55 \\
\hline 9.64 & 11.97 \\
\hline 8.82 & 14.4 \\
\hline 13.36 & 5.37 \\
\hline 63.18 & 7.82 \\
\hline 13.64 & 15.74 \\
\hline 21 & 13.4 \\
\hline 12.55 & 10.48 \\
\hline 13.45 & 14.25 \\
\hline 21.91 & 11.83 \\
\hline 14.36 & 13.24 \\
\hline 27.09 & 15.31 \\
\hline 22.27 & 6.86 \\
\hline 9.91 & 11.93 \\
\hline 13 & 12.52 \\
\hline 9.09 & 8.99 \\
\hline 12.36 & 13.9 \\
\hline
\end{tabular}

\begin{tabular}{|c|c|c|}
\hline \multicolumn{3}{|c|}{$\begin{array}{c}\text { Phosphate solubilization in } \\
\text { Pikovskaya's }\end{array}$} \\
\hline \multirow{2}{*}{$\begin{array}{l}\text { Broth } \\
(\mu \mathrm{g} / \mathrm{ml})\end{array}$} & \multicolumn{2}{|c|}{ Agar medium } \\
\hline & $\begin{array}{l}\text { with } \\
\text { BCP }\end{array}$ & without BCP \\
\hline 379 & ++ & + \\
\hline 502 & + & + \\
\hline 455 & + & + \\
\hline 239 & ++ & ++ \\
\hline 264 & ++ & ++ \\
\hline 550 & +++ & +++ \\
\hline 484 & + & ++ \\
\hline 383 & +++ & ++ \\
\hline 95 & ++ & + \\
\hline 139 & ++ & ++ \\
\hline 407 & + & ++ \\
\hline 356 & +++ & +++ \\
\hline 365 & + & + \\
\hline 306 & ++ & ++ \\
\hline 135 & ++ & + \\
\hline 88 & + & + \\
\hline 347 & ++ & + \\
\hline 335 & + & + \\
\hline 401 & +++ & +++ \\
\hline 518 & ++ & + \\
\hline 768 & +++ & +++ \\
\hline 278 & ++ & ++ \\
\hline 399 & + & +++ \\
\hline 194 & + & ++ \\
\hline
\end{tabular}


Table.6 Fluorescent Pseudomonas isolates inducing significant increase in root growth in different crop plants and their Indole acetic acid (IAA), PHB production and inorganic phosphate solubilization ability

\begin{tabular}{|c|c|c|c|c|c|c|c|}
\hline \multirow[t]{3}{*}{ S. No. } & \multirow[t]{3}{*}{ Isolates } & \multirow[t]{3}{*}{$\begin{array}{c}\text { Increase in } \\
\text { root } \\
\text { growth }\end{array}$} & \multirow[t]{3}{*}{$\begin{array}{c}\text { IAA } \\
\text { production } \\
(\mu \mathrm{g} / \mathrm{ml})\end{array}$} & \multirow[t]{3}{*}{$\begin{array}{c}\text { PHB } \\
\text { Production } \\
(\mathrm{mg} / \mathrm{ml})\end{array}$} & \multicolumn{3}{|c|}{$\begin{array}{c}\text { Phosphate } \\
\text { solubilization in } \\
\text { Pikovskaya's }\end{array}$} \\
\hline & & & & & \multirow{2}{*}{$\begin{array}{c}\text { Broth } \\
(\mu \mathrm{g} / \mathrm{ml})\end{array}$} & \multicolumn{2}{|c|}{ Agar medium } \\
\hline & & & & & & $\begin{array}{l}\text { with } \\
\mathrm{BCP}\end{array}$ & $\begin{array}{c}\text { without } \\
\text { BCP }\end{array}$ \\
\hline 1 & P67 & Rice & 13.91 & 7.56 & 550 & +++ & +++ \\
\hline 2 & P72 & Bottlegourd & 24 & 13.19 & 502 & + & + \\
\hline 3 & P129 & Bottlegourd & 21 & 13.4 & 306 & ++ & ++ \\
\hline 4 & P141 & Bottlegourd & 10.27 & 11.55 & 383 & +++ & ++ \\
\hline 5 & $\mathrm{P} 151$ & Bottlegourd & 13.45 & 14.25 & 88 & + & + \\
\hline 6 & P216 & Lathyrus & 9.91 & 11.93 & 768 & +++ & +++ \\
\hline 7 & P247 & Rice & 13 & 12.52 & 278 & ++ & ++ \\
\hline
\end{tabular}

Table.7 Fluorescent Pseudomonas isolates inducing significant reduction in root and shoot length in different crop plants and their Indole acetic acid (IAA), PHB production and inorganic phosphate solubilization ability

\begin{tabular}{|c|c|c|c|c|c|c|c|}
\hline $\begin{array}{c}\text { S. } \\
\text { No. }\end{array}$ & $\begin{array}{c}\text { Isolate } \\
\mathbf{S}\end{array}$ & $\begin{array}{c}\text { Inhibitory } \\
\text { effects on } \\
\text { root \& shoot } \\
\text { development }\end{array}$ & $\begin{array}{c}\text { IAA } \\
\text { production } \\
(\boldsymbol{\mu g} / \mathrm{ml})\end{array}$ & $\begin{array}{c}\text { PHB } \\
\text { Production } \\
(\mathbf{m g} / \mathbf{m l})\end{array}$ & \multicolumn{2}{|c|}{$\begin{array}{c}\text { Phosphate solubilization } \\
\text { in Pikovskaya's }\end{array}$} \\
\hline
\end{tabular}


Table.8 Fluorescent Pseudomonas isolates inducing significant reduction in root length in different crop plants and their Indole acetic acid (IAA), PHB production and inorganic phosphate solubilization ability

\begin{tabular}{|c|c|c|c|c|c|c|c|}
\hline \multirow[t]{3}{*}{ S. No. } & \multirow[t]{3}{*}{ Isolates } & \multirow[t]{3}{*}{$\begin{array}{l}\text { Inhibitory effects on } \\
\text { root development }\end{array}$} & \multirow[t]{3}{*}{$\begin{array}{l}\text { IAA } \\
\text { production } \\
(\mu \mathrm{g} / \mathrm{ml})\end{array}$} & \multirow[t]{3}{*}{$\begin{array}{c}\text { PHB } \\
\text { Production } \\
\text { (mg/ml) }\end{array}$} & \multicolumn{3}{|c|}{$\begin{array}{l}\text { Phosphate } \\
\text { solubilization in } \\
\text { Pikovskaya's }\end{array}$} \\
\hline & & & & & \multirow{2}{*}{$\begin{array}{l}\text { Broth } \\
(\mu \mathrm{g} / \mathrm{ml})\end{array}$} & \multicolumn{2}{|c|}{ Agar medium } \\
\hline & & & & & & $\begin{array}{l}\text { with } \\
\text { BCP }\end{array}$ & $\begin{array}{l}\text { without } \\
\text { BCP }\end{array}$ \\
\hline 1 & P72 & - & 24 & 13.19 & 502 & + & + \\
\hline 2 & P11 & Rice & 13.36 & 5.37 & 407 & + & ++ \\
\hline 3 & P216 & Rice; & 9.91 & 11.93 & 768 & +++ & +++ \\
\hline 4 & P5 & Greengram & 15.36 & 6.86 & 379 & ++ & + \\
\hline 5 & P6 & Chickpea & 8.09 & 2.67 & 264 & ++ & ++ \\
\hline 6 & P124 & Chickpea & 63.18 & 7.82 & 356 & +++ & +++ \\
\hline 7 & P143 & Lathyrus & 12.55 & 10.48 & 135 & ++ & + \\
\hline 8 & P151 & Lathyrus & 13.45 & 14.25 & 88 & + & + \\
\hline 9 & P247 & Greengram & 13 & 12.52 & 278 & ++ & ++ \\
\hline 10 & P161 & Greengram & 16.18 & 14.52 & 455 & + & + \\
\hline 11 & P99 & Greengram, Rice & 27.09 & 15.31 & 401 & +++ & +++ \\
\hline 12 & P76 & Greengram, Rice & 11.09 & 12.91 & 484 & + & ++ \\
\hline 13 & P141 & Lathyrus, Rice & 10.27 & 11.55 & 383 & +++ & ++ \\
\hline 14 & P67 & Chickpea, Greengram & 13.91 & 7.56 & 550 & +++ & +++ \\
\hline 15 & P176 & Chickpea, Greengram & 12.36 & 13.9 & 194 & + & ++ \\
\hline 16 & P85 & $\begin{array}{l}\text { Bottlegourd, } \\
\text { Greengram }\end{array}$ & 9.09 & 8.99 & 399 & + & +++ \\
\hline 17 & P233 & Bottlegourd, Lathyrus & 8.82 & 14.4 & 139 & ++ & ++ \\
\hline 18 & P179 & $\begin{array}{l}\text { Chickpea, Lathyrus, } \\
\text { Rice }\end{array}$ & 13.27 & 14.05 & 239 & ++ & ++ \\
\hline 19 & P201 & $\begin{array}{l}\text { Chickpea, Greengram, } \\
\text { Rice }\end{array}$ & 22.27 & 6.86 & 518 & ++ & + \\
\hline 20 & P205 & $\begin{array}{l}\text { Chickpea, Greengram, } \\
\text { Rice }\end{array}$ & 21.91 & 11.83 & 347 & ++ & + \\
\hline 21 & P126 & $\begin{array}{l}\text { Chickpea, Greengram, } \\
\text { Lathyrus }\end{array}$ & 13.64 & 15.74 & 365 & + & + \\
\hline 22 & P129 & $\begin{array}{l}\text { Chickpea, Greengram, } \\
\text { Lathyrus; }\end{array}$ & 21 & 13.4 & 306 & ++ & ++ \\
\hline 23 & P167 & $\begin{array}{l}\text { Bottlegourd, } \\
\text { Greengram, Lathyrus }\end{array}$ & 9.64 & 11.97 & 95 & ++ & + \\
\hline 24 & P248 & $\begin{array}{l}\text { Blackgram, Chickpea, } \\
\text { Greengram }\end{array}$ & 14.36 & 13.24 & 335 & + & + \\
\hline
\end{tabular}


Table.9 Fluorescent Pseudomonas isolates inducing significant reduction in shoot length in different crop plants and their Indole acetic acid (IAA), PHB production and inorganic phosphate solubilization ability

\begin{tabular}{|c|c|c|c|c|c|c|c|}
\hline \multirow[t]{3}{*}{ S. No. } & \multirow[t]{3}{*}{ Isolates } & \multirow[t]{3}{*}{$\begin{array}{l}\text { Inhibitory effects on shoot } \\
\text { development }\end{array}$} & \multirow{3}{*}{$\begin{array}{l}\text { IAA } \\
\text { production } \\
(\mu \mathrm{g} / \mathrm{ml})\end{array}$} & \multirow{3}{*}{$\begin{array}{c}\text { PHB } \\
\text { Production } \\
\text { (mg/ml) }\end{array}$} & \multicolumn{3}{|c|}{$\begin{array}{c}\text { Phosphate solubilization in } \\
\text { Pikovskaya's }\end{array}$} \\
\hline & & & & & \multirow{2}{*}{$\begin{array}{l}\text { Broth } \\
(\mu \mathrm{g} / \mathrm{ml})\end{array}$} & \multicolumn{2}{|c|}{ Agar medium } \\
\hline & & & & & & $\begin{array}{l}\text { with } \\
\text { BCP }\end{array}$ & $\begin{array}{l}\text { without } \\
\text { BCP }\end{array}$ \\
\hline 1 & P85 & Wheat & 09.09 & 8.99 & 399 & + & +++ \\
\hline 2 & P99 & Wheat & 27.09 & 15.31 & 401 & +++ & +++ \\
\hline 3 & P179 & Wheat & 13.27 & 14.05 & 239 & ++ & ++ \\
\hline 4 & P205 & Wheat; & 21.91 & 11.83 & 347 & 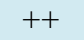 & + \\
\hline 5 & P248 & Wheat & 14.36 & 13.24 & 335 & + & + \\
\hline 6 & P151 & Blackgram; & 13.45 & 14.25 & 88 & + & + \\
\hline 7 & P247 & Bottlegourd & 13 & 12.52 & 278 & ++ & ++ \\
\hline 8 & P11 & Rice, Bottlegourd & 13.36 & 5.37 & 407 & + & ++ \\
\hline 9 & P129 & Rice, Wheat & 21 & 13.4 & 306 & ++ & ++ \\
\hline 10 & P67 & Bottlegourd, Wheat & 13.91 & 7.56 & 550 & +++ & +++ \\
\hline 11 & P126 & Blackgram, Wheat; & 13.64 & 15.74 & 365 & + & + \\
\hline 12 & P141 & Bottlegourd, Wheat; & 10.27 & 11.55 & 383 & +++ & ++ \\
\hline 13 & P201 & Bottlegourd, Wheat & 22.27 & 6.86 & 518 & ++ & + \\
\hline 14 & P216 & Bottlegourd, Wheat & 09.91 & 11.93 & 768 & +++ & +++ \\
\hline 15 & P72 & Bottlegourd, Rice, Wheat & 24 & 13.19 & 502 & + & + \\
\hline
\end{tabular}

Maximum root length $(24.83 \mathrm{~cm})$ and shoot length $(18.62 \mathrm{~cm})$ were recorded when seeds were treated with P233 and P99 respectively (Table 9). Seed treated with isolate P233 has $8.39 \mathrm{~cm}(33.8 \%)$ more root length and isolate P99 has $5.99 \mathrm{~cm}(32.16 \%)$ shoot length as compared to control. Fourteen isolates expressed plant growth promoting activity on blackgram. Isolates P6, P143, P176 and P233 were able to promote significantly root and shoot length, whereas isolates P5, P76, P85, P99, P11, P124, P141, P179, P201, P205, P216, P247, P248 promote significantly root length of blackgram.

Fluorescent Pseudomonas isolates inducing significant increase in root and shoot growth in different crop plants

Increase in root and shoot length in one crop: P72 Chickpea; P141 Greengram; P151 Rice. Increase in root and shoot length in two crops: P233 Blackgram, Rice; P124 Bottlegourd,
Wheat. Three fluorescent Pseudomonas isolates increased the root and shoot length of the same crop: P6, P143, P176 (Blackgram); P76, P99, P167 (Bottlegourd).

Isolates inducing significant increase in shoot growth in different crop plants

It was observed that Fluorescent Pseudomonas isolates the frequency of inducing shoot length was more as compared to root length.

In the order of decreasing frequency of fluorescent Pseudomonas isolates inducing increased shoot growth in different crops is as follows: Wheat (20)> Chickpea (19)> Lathyrus (16)> Greengram (14)> Blackgram (13)> Bottlegourd (5)> Rice (3).

Fluorescent Pseudomonas isolates P5, P6, P11, P124 did not increased the shoot length in rice or wheat. Among cereals wheat was 
more responsive and expressed increased shoot length with 20 different Fluorescement Pseudomonas isolates whereas rice expressed increased shoot length with only three isolates P216, P85 and P176.

Bottlegourd are very responsive to IAA but expressed increased shoot length with only P126, P143, P248. Fluorescent Pseudomonas isolate P124 was the highest IAA producer but was not able to induce increased root or shoot length in bottlegourd.

Fluorescent Pseudomonas isolates increased the shoot length only in one legume crop P161 Chickpea; P72 Lathyrus; P179 Blackgram

Fluorescent Pseudomonas isolates increased the shoot length in any two legume crop P5, P248 Blackgram, Lathyrus; P167 Greengram, Lathyrus; P126 Chickpea, Lathyrus; P67, P143, P233 Chickpea, Greengram; P76, P141 Blackgram, Chickpea.

Fluorescent Pseudomonas isolates increased the shoot length in three legumes crop P6, P129, P151, P176 Chickpea, Greengram, Lathyrus; P85, P205 Blackgram, Chickpea, Lathyrus; P216 Blackgram, Chickpea, Greengram

Fluorescent Pseudomonas isolates increase the shoot length in all four legumes (Blackgram, Chickpea, Greengram, Lathyrus) P11, P124, P99, P201, P247.

Isolates inducing significant increase in root growth in different crop plants

The frequency of Fluorescent Pseudomonas isolates inducing increased root length was four (P72, P129, P141 and P151) whereas only two P67 and P247 induced increased root length in rice and only one in lathyrus by P216.
PGPR can alter root architecture and promote plant development with the production of different phytohormones like IAA, gibberellic acid and cytokinins (Kloepper et al., 2007). Similarly, significant shoot growths in maize and rice dwarf mutants were promoted by gibberellins-like substances excreted by Azospirillum spp. (Boiero et al., 2007). IAAmediated ethylene production could increase root biomass, root hair number and consequently the root surface area of PGPR inoculated tomato plants (Ribaudo et al., 2006). Involvement of PGPR formulated cytokinins were also observed in root initiation, cell division, cell enlargement and increase in root surface area of crop plants through enhanced formation of lateral and adventitious roots(Werner et al., 2003). Recently, it has been established that the working pathways of these phytostimulators leading to overall development in crop plants are differently regulated by catabolite repression (Zaidi et al., 2009) as physiological regulator of biofilm formation.IAA biosynthesis has been correlated with stimulation of root proliferation by rhizosphere bacteria (Persello-Cartieaux et al., 2003; Spaepen et al., 2007), which enhanced uptake of nutrients by the associated plants (Lifshitz et al., 1987). Moreover, inoculation with an Azospirillum brasilense Sp245 mutant strain, strongly reduced in auxin biosynthesis or addition of increasing concentrations of exogenous auxin to the plant growth medium, indicated that the differential response to A. brasilense Sp245 among the common bean (Phaseolus vulgaris L.) genotypes is related to the bacterial produced auxin (Remans et al., 2008). IAA affects plant cell division, extension, and differentiation; stimulates seed and tuber germination; increases the rate of xylem and root development; controls processes of vegetative growth; initiates lateral and adventitious root formation; mediates responses to light, gravity and florescence; 
affects photosynthesis, pigment formation, biosynthesis of various metabolites, and resistance to stressful conditions (Tsavkelova et al., 2006; Spaepen and Vanderleyden 2011). IAA synthesized by bacteria may be involved at different levels in plant-bacterial interactions. In particular, plant growth promotion and root nodulation are both affected by IAA. The role of IAA that was synthesized by the PGPB Pseudomonas putida GR12-2 in the development of canola roots was studied following the construction of an IAA-deficient mutant of this strain (Patten and Glick 2002a). Seed inoculation with wild-type $P$. putida GR12-2 induced the formation of roots that were $35-50 \%$ longer than the roots from seeds treated with the IAA-deficient mutant and the roots from uninoculated seeds. On the other hand, inoculation of mung bean cuttings with a mutant of the same strain (Xie et al., 1996), which overproduces IAA, yielded a much greater number of shorter roots compared with controls (Mayak et al., 1999).

This result was explained by the combined effect of auxin on growth promotion and inhibition of root elongation by ethylene(Jackson 1991). The bacterial IAA that was incorporated by the plant stimulated the activity of the enzyme ACC synthase, resulting in increased synthesis of ACC (Jackson 1991), and a subsequent rise in ethylene that inhibited root elongation (Riov and Yang 1989). Overall, bacterial IAA increases root surface area and length, and thereby provides the plant has greater access to soil nutrients. In addition, bacterial IAA loosens plant cell walls and as a result facilitates an increasing amount of root exudation that provides additional nutrients to support the growth of rhizosphere bacteria.

It was observed that Fluorescent Pseudomonas isolates also reduced root shoot length as compared un-treated control.
Fluorescent Pseudomonas isolates inducing reduced root and shoot length in different crop plants

In the order of decreasing frequency of fluorescent Pseudomonas isolates inducing reduction in root and shoot length in Bottlegourd (4), Rice (1), Lathyrus (1) and Wheat (1)

Fluorescent Pseudomonas isolates inducing reduced root length in different crop plants

Except isolate P72 all the isolates induced reduction in root length. Because seed biopriming places the bacterium directly in contact with soil and after germination with rhizoplane / rhizosphere of the germinated seed, suggesting that the compatible / incompatible interaction between the host and bacterium might result into induced increased or decreased growth of the root. This might be the reason why the frequency of fluorescent Pseudomonas isolates inducing reduction in root length (23 out of 24 isolates) in different crop plants was very high as compared to isolates inducing reduction in shoot length (16 out of 24 isolates).

Fluorescent Pseudomonas isolates inducing reduced shoot length in different crop plants

In the order of decreasing frequency of fluorescent Pseudomonas isolates inducing reduction in shoot length in Wheat (12), Bottlegourd (7), Rice (3) Blackgram (2).

Inhibitory effect of some deleterious rhizobacteria through IAA secretion has been related to various bacterial species including Enterobacter taylorae, Klebsiella planticola, Alcaligenes faecalis, Xanthomonas maltophila, Pseudomonas sp. and Flavobacterium sp. (Sarwar and Kremer 1995; Suzuki et al., 2003). Mutants of 
Pseudomonas putida that produced high levels of IAA inhibited root growth of seedlings of canola (Brassica campestris) by ca. 33\% (Xie et al., 1996). Thus, ambiguity about effect of IAA on growth of root, shoot and rate of seedling emergence has been reported (Freitas and Germida 1990; Sarwar and Kremer 1995; Barazani and Friedman 1999) (Table 2-6). Despite the potential of allelopathic bacteria and growth-mediating allelochemicals in agriculture, it is one of the poorly understood areas of plantmicrobe interactions. Further work is needed to characterize bacteria and allelochemicals from the rhizosphere soil and to study their effect on the crop plants.

\section{References}

Agrawal T, Kotasthane AS, Kushwah R (2015) Genotypic and phenotypic diversity of polyhydroxybutyrate (PHB) producing Pseudomonas putida isolates of Chhattisgarh region and assessment of its phosphate solubilizing ability. 3 Biotech 5:45-60.

Ahmad F, Ahmad I, Khan MS (2008) Screening of free-living rhizospheric bacteria for their multiple plant growth promoting activities. Microbiol Res 163:173-181.

Ahmad F, Ahmad I, Khan MS (2005) Indole acetic acid production by the indigenous isolates of Azotobacter and fluorescent Pseudomonas in the presence and absence of tryptophan. Turk J Biol 29:29-34.

Barazani OZ, Friedman J (1999) Is IAA the major root growth factor secreted from plantgrowth-mediating bacteria? J Chem Ecol 25:2397-2406.

Belimov AA, Dodd IC, Hontzeas N, et al., (2009a) Rhizosphere bacteria containing 1aminocyclopropane- 1- carboxylate deaminase increase yield of plants grown in drying soil via both local and systemic hormone signalling. New Phytol 181:413423.

Belimov AA, Dodd IC, Safronova VI, et al., (2007) Pseudomonas brassicacearum strain Am3 containing 1-aminocyclopropane-1- carboxylate deaminase can show both pathogenic and growth-promoting properties in its interaction with tomato. $\mathbf{J}$ Exp Bot 58:1485-1495.

Belimov AA, Dodd IC, Safronova VI, et al., (2009b) ACC deaminase-containing rhizobacteria improve vegetative development and yield of potato plants grown under water-limited conditions. Asp Appl Biol 163-169.

Bergsma-Vlami M, Prins ME, Staats M, Raaijmakers JM (2005) Assessment of genotypic diversity of antibiotic-producing Pseudomonas species in the rhizosphere by denaturing gradient gel electrophoresis. Appl Environ Microbiol 71:993-1003.

Bianco C, Defez R (2009) Medicago truncatula improves salt tolerance when nodulated by an indole-3-acetic acid-overproducing Sinorhizobium meliloti strain. J Exp Bot 60:3097-3107.

Bianco C, Defez R (2010) Improvement of phosphate solubilization and Medicago plant yield by an indole-3-acetic acidoverproducing strain of Sinorhizobium meliloti. Appl Environ Microbiol 76:46264632.

Boiero L, Perrig D, Masciarelli O, et al., (2007) Phytohormone production by three strains of Bradyrhizobium japonicum and possible physiological and technological implications. Appl Microbiol Biotechnol 74:874-880.

Botelho GR, Mendonça-Hagler LC (2006) Fluorescent Pseudomonads associated with the rhizosphere of crops: an overview. Brazilian J Microbiol 37:401-416.

Brown ME (1974) Seed and root bacterization. Annu Rev Phytopathol 12:181-197.

Chung A, Liu Q, Ouyang S-P, et al., (2009) Microbial production of 3hydroxydodecanoic acid by pha operon and fadBA knockout mutant of Pseudomonas putida KT2442 harboring tesB gene. Appl Microbiol Biotechnol 83:513-519.

Contreras-Cornejo HA, Macías-Rodríguez L, Cortés-Penagos C, López-Bucio J (2009) Trichoderma virens, a plant beneficial fungus, enhances biomass production and promotes lateral root growth through an 
auxin-dependent mechanism in Arabidopsis. Plant Physiol 149:1579-1592.

De-Bashan LE, Hernandez J-P, Nelson KN, et al., (2010) Growth of quailbush in acidic, metalliferous desert mine tailings: effect of Azospirillum brasilense Sp6 on biomass production and rhizosphere community structure. Microb Ecol 60:915-927.

Dos Santos VAP, Heim S, Moore ERB, et al., (2004) Insights into the genomic basis of niche specificity of Pseudomonas putida KT2440. Environ Microbiol 6:1264-1286.

Dubeikovsky AN, Mordukhova EA, Kochetkov V $\mathrm{V}$, et al., (1993) Growth promotion of blackcurrant softwood cuttings by recombinant strain Pseudomonas fluorescens BSP53a synthesizing an increased amount of indole-3-acetic acid. Soil Biol Biochem 25:1277-1281.

Durner R, Zinn M, Witholt B, Egli T (2001) Accumulation of poly [(R)- 3- hydroxyalkanoates] in Pseudomonas oleovorans during growth in batch and chemostat culture with different carbon sources. Biotechnol Bioeng 72:278288.

Dworkin M, Foster JW (1958) Experiments with some microorganisms which utilize ethane and hydrogen. J Bacteriol 75:592.

Egamberdieva D (2009) Alleviation of salt stress by plant growth regulators and IAA producing bacteria in wheat. Acta Physiol Plant 31:861-864.

Elbahloul Y, Steinbüchel A (2009) Large-scale production of poly (3-hydroxyoctanoic acid) by Pseudomonas putida GPo1 and a simplified downstream process. Appl Environ Microbiol 75:643-651.

Fravel DR (2005) Commercialization and implementation of biocontrol 1. Annu Rev Phytopathol 43:337-359.

Fravel DR (1988) Role of antibiosis in the biocontrol of plant diseases*. Annu Rev Phytopathol 26:75-91.

Freitas JR de, Germida JJ (1990) Plant growth promoting rhizobacteria for winter wheat. Can J Microbiol 36:265-272.

Glick BR (1995) The enhancement of plant growth by free-living bacteria. Can J Microbiol 41:109-117.
Gordon SA, Weber RP (1951) Colorimetric estimation of indoleacetic acid. Plant Physiol 26:192.

Gravel V, Antoun H, Tweddell RJ (2007) Growth stimulation and fruit yield improvement of greenhouse tomato plants by inoculation with Pseudomonas putida or Trichoderma atroviride: possible role of indole acetic acid (IAA). Soil Biol Biochem 39:19681977.

Gulati A, Rahi P, Vyas P (2008) Characterization of phosphate-solubilizing fluorescent pseudomonads from the rhizosphere of seabuckthorn growing in the cold deserts of Himalayas. Curr Microbiol 56:73-79.

Han J, Sun L, Dong X, et al., (2005) Characterization of a novel plant growthpromoting bacteria strain Delftia tsuruhatensis HR4 both as a diazotroph and a potential biocontrol agent against various plant pathogens. Syst Appl Microbiol 28:66-76. doi: http://dx.doi.org/10.1016/j.syapm.2004.09.0 03

Hartmann R, Hany R, Geiger T, et al., (2004) Tailored Biosynthesis of Olefinic MediumChain-Length Poly [(R)-3hydroxyalkanoates] in Pseudomonas $\mathrm{p}$ utida GPo1 with Improved Thermal Properties. Macromolecules 37:6780-6785.

Hoffmann N, Rehm BHA (2004) Regulation of polyhydroxyalkanoate biosynthesis in Pseudomonas putida and Pseudomonas aeruginosa. FEMS Microbiol Lett 237:1-7.

Holloway BW (1992) Pseudomonas in the late twentieth century. In: FEMS Symposium. Plenum Press, $\mathrm{p} 1$

Hossain MM, Sultana F, Kubota M, et al., (2007) The plant growth-promoting fungus Penicillium simplicissimum GP17-2 induces resistance in Arabidopsis thaliana by activation of multiple defense signals. Plant Cell Physiol 48:1724-1736.

Jackson MB (1991) Ethylene in root growth and development. plant Horm Ethyl 159-181.

Khalid A, Tahir S, Arshad M, Zahir ZA (2005) Relative efficiency of rhizobacteria for auxin biosynthesis in rhizosphere and nonrhizosphere soils. Soil Res 42:921-926.

Kloepper JW, Gutierrez-Estrada A, McInroy JA (2007) Photoperiod regulates elicitation of 
growth promotion but not induced resistance by plant growth-promoting rhizobacteria. Can J Microbiol 53:159-167.

Law JH, Slepecky RA (1961) Assay of poly- $\beta$ hydroxybutyric acid. J Bacteriol 82:33-36.

Leisinger T, Margraff R (1979) Secondary metabolites of the fluorescent pseudomonads. Microbiol Rev 43:422.

Lemanceau P (1992) beneficial-effects of rhizobacteria on plants-example of fluorescent Pseudomonas SPP. Agronomie 12:413-437.

Leong J (1986) Siderophores: their biochemistry and possible role in the biocontrol of plant pathogens. Annu Rev Phytopathol 24:187209.

Lifshitz R, Kloepper JW, Kozlowski M, et al., (1987) Growth promotion of canola (rapeseed) seedlings by a strain of Pseudomonas putida under gnotobiotic conditions. Can J Microbiol 33:390-395.

Liu M, González JE, Willis LB, Walker GC (1998) A novel screening method for isolating exopolysaccharide-deficient mutants. Appl Environ Microbiol 64:4600 4602.

Madison LL, Huisman GW (1999) Metabolic engineering of poly (3-hydroxyalkanoates): from DNA to plastic. Microbiol Mol Biol Rev 63:21-53.

Mayak S, Tirosh T, Glick BR (1999) Effect of wild-type and mutant plant growthpromoting rhizobacteria on the rooting of mung bean cuttings. J Plant Growth Regul 18:49-53.

Mayak S, Tirosh T, Glick BR (2004) Plant growth-promoting bacteria confer resistance in tomato plants to salt stress. Plant Physiol Biochem 42:565-572. doi: 10.1016/j.plaphy.2004.05.009

McSpadden Gardener BB, Mavrodi D V, Thomashow LS, Weller DM (2001) A rapid polymerase chain reaction-based assay characterizing rhizosphere populations of 2 , 4-diacetylphloroglucinol-producing bacteria. Phytopathology 91:44-54.

Meijnen J-P, de Winde JH, Ruijssenaars HJ (2008) Engineering Pseudomonas putida S12 for efficient utilization of D-xylose and L-arabinose. Appl Environ Microbiol 74:5031-5037.
Murphy J, Riley JP (1962) A modified single solution method for the determination of phosphate in natural waters. Anal Chim Acta 27:31-36.

Patten CL, Glick BR (2002a) Role of Pseudomonas putida indoleacetic acid in development of the host plant root system. Appl Environ Microbiol 68:3795-3801.

Patten CL, Glick BR (2002b) Regulation of indoleacetic acid production in Pseudomonas putida GR12-2 by tryptophan and the stationary-phase sigma factor RpoS. Can J Microbiol 48:635-642.

Patten CL, Glick BR (1996) Bacterial biosynthesis of indole-3-acetic acid. Can J Microbiol 42:207-220.

Persello- Cartieaux F, Nussaume L, Robaglia C (2003) Tales from the underground: molecular. Plant Cell Environ 26:189-199.

Pilet P-E, Saugy M (1987) Effect on Root Growth of Endogenous and Applied IAA and ABA A Critical Reexamination. Plant Physiol 83:33-38.

Raghothama KG (1999) Phosphate acquisition. Annu Rev Plant Biol 50:665-693.

Rajkumar M, Nagendran R, Lee KJ, et al., (2006) Influence of plant growth promoting bacteria and $\mathrm{Cr} 6+$ on the growth of Indian mustard. Chemosphere 62:741-748.

Ramamoorthy V, Viswanathan R, Raguchander T, et al., (2001) Induction of systemic resistance by plant growth promoting rhizobacteria in crop plants against pests and diseases. Crop Prot 20:1-11. doi: http://dx.doi.org/10.1016/S02612194(00)00056-9

Ramos JL, Krell T, Daniels C, et al., (2009) Responses of $<$ i $>$ Pseudomonas $\langle\mathrm{i}>$ to small toxic molecules by a mosaic of domains. Curr Opin Microbiol 12:215-220.

Remans R, Beebe S, Blair M, et al., (2008) Physiological and genetic analysis of root responsiveness to auxin-producing plant growth-promoting bacteria in common bean (Phaseolus vulgaris L.). Plant Soil 302:149161.

Ribaudo CM, Krumpholz EM, Cassán FD, et al., (2006) Azospirillum sp. promotes root hair development in tomato plants through a mechanism that involves ethylene. J Plant Growth Regul 25:175-185. 
Riov J, Yang SF (1989) Ethylene and auxinethylene interaction in adventitious root formation in mung bean cuttings. In: Biochemical and Physiological Aspects of Ethylene Production in Lower and Higher Plants. Springer, pp 151-156

Rodríguez H , Fraga R (1999) Phosphate solubilizing bacteria and their role in plant growth promotion. Biotechnol Adv 17:319339.

Rojo F (2010) Carbon catabolite repression in Pseudomonas: optimizing metabolic versatility and interactions with the environment. FEMS Microbiol Rev 34:658-684.

Sarwar M, Kremer RJ (1995) Determination of bacterially derived auxins using a microplate method. Lett Appl Microbiol 20:282-285.

Shahzad SM, Khalid A, Arshad M (2010) Screening rhizobacteria containing ACCdeaminase for growth promotion of chickpea seedlings under axenic conditions. Soil Environ 29:38-46.

Sheng X-F, Xia J-J (2006) Improvement of rape (Brassica napus) plant growth and cadmium uptake by cadmium-resistant bacteria. Chemosphere 64:1036-1042.

Sneath PHA, Mair NS, Sharpe ME, Holt JG (1986) Bergy's manual of systematic bacteriology, Vol. 2.

Spaepen S, Vanderleyden J (2011) Auxin and plant-microbe interactions. Cold Spring Harb Perspect Biol 3:a001438.

Spaepen S, Vanderleyden J, Remans R (2007) Indole-3-acetic acid in microbial and microorganism-plant signaling. FEMS Microbiol Rev 31:425-448.

Sun Z, Ramsay JA, Guay M, Ramsay BA (2007) Fermentation process development for the production of medium-chain-length poly-3hyroxyalkanoates. Appl Microbiol Biotechnol 75:475-485.

Suzuki S, He Y, Oyaizu H (2003) Indole-3-acetic acid production in Pseudomonas fluorescens HP72 and its association with suppression of creeping bentgrass brown patch. Curr Microbiol 47:138-143.

Swain MR, Naskar SK, Ray RC (2007) Indole-3acetic acid production and effect on sprouting of yam (Dioscorea rotundata L.) minisetts by Bacillus subtilis isolated from culturable cowdung microflora. Polish $\mathrm{J}$ Microbiol 56:103.

Taghavi S, Garafola C, Monchy S, et al., (2009) Genome survey and characterization of endophytic bacteria exhibiting a beneficial effect on growth and development of poplar trees. Appl Environ Microbiol 75:748-757.

Taiz L, Zeiger E (1991) Plant Physiology., The Benjamin.

Takahashi K, Murakami T, Kamata A, et al., (1994) Pharmacokinetic analysis of the absorption enhancing action of decanoic acid and its derivatives in rats. Pharm Res 11:388-392.

Tanimoto E (2005) Regulation of root growth by plant hormones-roles for auxin and gibberellin. CRC Crit Rev Plant Sci 24:249-265.

Timmis KN (2002) Pseudomonas putida: a cosmopolitan opportunist par excellence. Environ Microbiol 4:779-781.

Tsavkelova EA, Klimova SY, Cherdyntseva TA, Netrusov AI (2006) Microbial producers of plant growth stimulators and their practical use: a review. Appl Biochem Microbiol 42:117-126.

Vazquez P, Holguin G, Puente ME, et al., (2000) Phosphate-solubilizing microorganisms associated with the rhizosphere of mangroves in a semiarid coastal lagoon. Biol Fertil Soils 30:460-468.

Vessey JK (2003) Plant growth promoting rhizobacteria as biofertilizers. Plant Soil 255:571-586.

Vo MT, Lee K-W, Jung Y-M, Lee Y-H (2008) Comparative effect of overexpressed phaJ and fabG genes supplementing (R)-3hydroxyalkanoate monomer units on biosynthesis of mcl-polyhydroxyalkanoate in Pseudomonas putida KCTC1639. J Biosci Bioeng 106:95-98.

Wang L, Armbruster W, Jendrossek D (2007) Production of medium-chain-length hydroxyalkanoic acids from Pseudomonas putida in $\mathrm{pH}$ stat. Appl Microbiol Biotechnol 75:1047-1053.

Wang Q, Nomura CT (2010) Monitoring differences in gene expression levels and polyhydroxyalkanoate (PHA) production in $<$ i $>$ Pseudomonas putida $</ \mathrm{i}>\mathrm{KT} 2440$ 
grown on different carbon sources. J Biosci Bioeng 110:653-659.

Wani PA, Khan MS, Zaidi A (2008) Effect of metal-tolerant plant growth-promoting Rhizobium on the performance of pea grown in metal-amended soil. Arch Environ Contam Toxicol 55:33-42.

Wani PA, Khan MS, Zaidi A (2007) Effect of metal tolerant plant growth promoting Bradyrhizobium sp.(vigna) on growth, symbiosis, seed yield and metal uptake by greengram plants. Chemosphere 70:36-45.

Weller DM (2007) Pseudomonas biocontrol agents of soilborne pathogens: looking back over 30 years. Phytopathology 97:250-256.

Weller DM, Raaijmakers JM, Gardener BBM, Thomashow LS (2002) Microbial populations responsible for specific soil suppressiveness to plant pathogens 1 . Annu Rev Phytopathol 40:309-348.

Werner T, Motyka V, Laucou V, et al., (2003) Cytokinin-deficient transgenic Arabidopsis plants show multiple developmental alterations indicating opposite functions of cytokinins in the regulation of shoot and root meristem activity. Plant Cell 15:25322550.

Wu X, Monchy S, Taghavi S, et al., (2011) Comparative genomics and functional analysis of niche- specific adaptation in Pseudomonas putida. FEMS Microbiol Rev 35:299-323.

Xie H, Pasternak JJ, Glick BR (1996) Isolation and characterization of mutants of the plant growth-promoting rhizobacterium Pseudomonas putida GR12-2 that overproduce indoleacetic acid. Curr Microbiol 32:67-71.

Zaidi A, Khan M, Ahemad M, Oves M (2009) Plant growth promotion by phosphate solubilizing bacteria. Acta Microbiol Immunol Hung 56:263-284.

\section{How to cite this article:}

Priyanka, Anil S. Kotasthane, Ashish Pradhan, Umesh Shinde, Toshy Agrawal, Najam Waris Zaidi and Singh, U.S. 2018. Host Specific Plant Growth Promoting Activity of IAA Producing and Phosphate Solubilizing Fluorescent Pseudomonas. Int.J.Curr.Microbiol.App.Sci. 7(02): 3511-3532. doi: https://doi.org/10.20546/ijcmas.2018.702.418 